\title{
Mistargeted mitochondrial proteins activate a proteostatic response in the cytosol
}

Lidia Wrobel, ${ }^{1,8}$ Ulrike Topf, ${ }^{1,8}$ Piotr Bragoszewski, ${ }^{1,9}$ Sebastian Wiese, ${ }^{2,3,4,9}$ Malgorzata E. Sztolsztener, ${ }^{1}$ Silke Oeljeklaus, ${ }^{2}$ Aksana Varabyova, ${ }^{1}$ Maciej Lirski, ${ }^{5}$ Piotr Chroscicki, ${ }^{1}$ Seweryn Mroczek, ${ }^{6,5}$ Elzbieta Januszewicz, ${ }^{1}$ Andrzej Dziembowski, ${ }^{5,6}$ Marta Koblowska, ${ }^{7,5}$ Bettina Warscheid, ${ }^{2,3, * *} \&$ Agnieszka Chacinska, ${ }^{1, *}$

${ }^{1}$ International Institute of Molecular and Cell Biology, 02-109 Warsaw, Poland

${ }^{2}$ Department of Biochemistry and Functional Proteomics, Faculty of Biology and BIOSS Centre for Biological Signalling Studies, University of Freiburg, D-79104 Freiburg, Germany ${ }^{3}$ ZBSA Centre for Biological Systems Analysis, University of Freiburg, D-79104 Freiburg, Germany

${ }^{4}$ current address: Core Unit Mass Spectrometry and Proteomics, Medical Faculty, Ulm University, D-89081 Ulm, Germany

${ }^{5}$ Institute of Biochemistry and Biophysics Polish Academy of Sciences, 02-106 Warsaw, Poland

${ }^{6}$ Department of Genetics and Biotechnology, Faculty of Biology, University of Warsaw, 02106 Warsaw, Poland

${ }^{7}$ Laboratory of Systems Biology, Faculty of Biology, University of Warsaw, 02-106 Warsaw, Poland

\footnotetext{
${ }^{8}$ These authors contributed equally to this work

${ }^{9}$ These authors contributed equally to this work
} 
*Corresponding author. Tel: +48 22597 0779; Fax: +48 22597 0715; E-mail: achacinska@iimcb.gov.pl

**Corresponding author. Tel: +49 761203 2690; Fax: +49 761203 2601; E-mail: bettina.warscheid@biologie.uni-freiburg.de 
The vast majority of the mitochondrial proteome originates from nuclear genes and is transported into the organelle after synthesis in the cytosol. Complex machineries, which maintain the specificity of protein import and sorting, include the TIM23 translocase responsible for the transfer of precursor proteins into the matrix and the MIA machinery required for the biogenesis of intermembrane space proteins. Dysfunctions of mitochondrial protein sorting pathways result in diminishing specific substrate proteins, followed by systemic pathology of the organelle and organismal death $^{1-4}$. Cellular responses that are caused by accumulation of mitochondrial precursor proteins in the cytosol are largely unknown. We show a comprehensive picture of the changes in the cellular transcriptome and proteome in response to the mitochondrial import defect and precursor over-accumulation stress. We identify pathways that protect the cell against mitochondrial biogenesis defects by inhibiting protein synthesis and by activation of the proteasome, a major machine for cellular protein clearance. The proteasomal activity is modulated in proportion to the quantity of mislocalized mitochondrial precursor proteins in the cytosol. We propose that this type of unfolded protein response activated by mistargeting of proteins (UPRam) is beneficial for the cells. UPRam provides a means for buffering the consequences of physiological slowdown in mitochondrial protein import and for counteracting pathologies that are caused or contributed by mitochondrial dysfunction. 
The mitochondrial intermembrane space import and assembly (MIA) machinery constitutes one of the essential protein translocation pathways into mitochondria and is responsible for the import of proteins destined to the intermembrane space (IMS) of mitochondria ${ }^{1-4}$. The RNA sequencing (RNA-Seq) analysis of mia40-4int $t^{5,6}$, a yeast temperature-sensitive mutant defective for the protein import into the IMS, versus wild-type cells was performed under permissive growth conditions to avoid cumulative consequences of broad mitochondrial dysfunction (Supplementary Table 1). Transcripts for cytosolic ribosomal proteins and proteins involved in translation, but not mitochondrial ribosomal proteins, were decreased (Fig. 1a and Extended Data Fig. 1a-c). Thus, changes in the transcriptome could not be directly translated into protein abundance. Next, the cellular proteomes of mia40-4int $\mathrm{S}$ and wild-type $^{\mathrm{S}}$ cells were determined under permissive growth conditions using stable isotope labelling by amino acids in cell culture $\left(\right.$ SILAC) ${ }^{7}$ (Supplementary Table 2, Extended Data Fig. 1d-g). Sensitive MIA substrates were significantly decreased in the mia40-4int $\mathrm{S}$ proteome (Supplementary Table 3, Extended Data Fig. 1h-k) because they were not maintained upon mitochondrial import inhibition ${ }^{8}$.

We determined the relative abundance of 2,564 proteins. A small fraction $(11 \%)$ exhibited significant changes in abundance with 112 down- and 174 upregulated proteins in mia40-4int ${ }^{\mathrm{S}}$ (Supplementary Table 3, Extended Data Fig. 1k). Localization and gene ontology analysis revealed the modulation of the structure and function of genetic information and reshaping of metabolic networks in mia40-4int ${ }^{\mathrm{S}}$ (Extended Data Fig. 2a, b). Consistent with RNA-Seq (Fig. 1a), a class of proteins that constitute the cytosolic ribosome were downregulated (Fig. 1b, Extended Data Fig. 2b, c). Under restrictive growth conditions an imbalance in the ratio between $25 \mathrm{~S}$ and $18 \mathrm{~S}$ rRNA (Fig. 1c, d) and a change in ribosome content with less prominent polysomes in the mia40-4int mutants (Extended Data Fig. 2d-f) were observed. Interestingly, the mia40-4int mutant exhibited a decrease in the protein 
synthesis (Fig. 1e), but massive cellular death was excluded (Extended Data Fig. 3a, b). The mia40-4int cells transformed with wild-type MIA40 exhibited normal protein synthesis rate demonstrating that the translation defect depends on mia40-4int (Fig. 1e, Extended Data Fig. $3 c)$.

The ubiquitin-proteasome system (UPS) ${ }^{9-12}$ is involved in the degradation of MIA substrate proteins ${ }^{8,13}$. Abundance of many proteins involved in the UPS did not change in mia40-4int ${ }^{\mathrm{S}}$, including the core proteasomal subunits (Supplementary Table 3, Extended Data Fig. 2d). Components of the proteasome assembly chaperone complex, Irc25/Poc3 and Poc $4^{14-17}$, significantly increased in mia40-4int ${ }^{\mathrm{S}}$ (Fig. 1f) despite non-significant changes at the mRNA level (Extended Data Fig. 3d). Other assembly chaperones, Ump1, Pba1/Poc1, and Add66/Poc2/Pba2 ${ }^{14-17}$, showed a tendency to increase, whereas the stress-inducible proteasome chaperone Adc17/Tma17 ${ }^{18}$ did not change (Supplementary Table 3). Under restrictive growth conditions ubiquitinated protein species were decreased in mia40-4int and the effect was complemented by MIA40 (Fig. 1g). The abundance of ubiquitinated species may mirror translation efficiency because newly synthesized proteins constitute a significant fraction of polyubiquitinated proteins in the cell ${ }^{19}$. However, the proteasomal inhibitor MG132 attenuated the difference in ubiquitination between wild-type and mutant cells, suggesting acceleration in mia40-4 protein turnover (Fig. 1g). The mia40-4int cells exhibited higher proteasomal activity than wild-type cells and this effect was rescued by MIA40 (Fig. 1h, Extended Data Fig. 4a-c). Applying restrictive temperatures to wild-type cells did not stimulate proteasomal activity (Extended Data Fig. 4d). Furthermore, other plasmid-borne conditional mia40 mutants ${ }^{5,6}$ with a phenotype milder than mia40-4int showed both a clear decrease in ubiquitinated species and an increase in proteasomal activity (Extended Data Fig. $4 e, f)$. 
Overexpression of Mia40 improved protein import into the mitochondrial IMS in human cells ${ }^{20}$ and in yeast as determined by an in organello assay (Extended Fig. 5a-c) but did not significantly influence the abundance of mitochondrial proteins (Extended Data Fig. 5d). However, when the MIA pathway was challenged by overproduced Pet $191_{\mathrm{FLAG}}{ }^{8}$, this protein was more efficiently localized to mitochondria (Fig. 1i and Extended Data Fig. 5e, f). The more productive removal of precursors from the cytosol by mitochondria with elevated Mia40 levels resulted in decreased proteasomal activity (Fig. 1j).

The import of a large fraction of mitochondrial proteins relies on the electrochemical potential of the inner mitochondrial membrane (IM potential $)^{1-4}$. Cells treated with the chemical uncoupler $\mathrm{CCCP}$ to dissipate the IM potential accumulated non-imported mitochondrial proteins in their longer unprocessed precursor forms (with the mitochondrial targeting sequence, called presequences ${ }^{1-4}$ ). During the chase in the absence of CCCP precursor proteins diminished (Fig. 2a, Extended Data Fig. 6a, b). Following the accumulation of mitochondrial precursors in the cytosol, a significant stimulation of the proteasome was observed (Fig. 2b). Similar accumulation of precursor proteins was observed in temperaturesensitive mutants of the TIM23 translocase and motor complex, pam 18, pam16 and $\operatorname{tim} 17^{21,22}$ (Fig. 2c, Extended Data Fig. 6c). These precursor forms were found in the cytosol (Fig. 2d, Extended Data Fig. 6d). The pam 18 and pam 16 mutants did not show any major changes in protein abundance (Extended Data Fig. 6e). However, similar to mia40, the pam18, pam16, and tim17 mutants exhibited a clear decrease in ubiquitinated species and increase in proteasomal activity (Fig. 2e, f, Extended Data Fig. 6f-h). Although we did not detect any change in ribosomal proteins or rRNA content (Extended Data Fig. 6e, i), protein synthesis was decreased and was accompanied by an increase in monosomes in pam16 cells (Fig. 2g, Extended Data Fig. 6j, k). Thus, the defective import of proteins into mitochondria leads to a response that regulates the cellular protein homeostasis through two arms, the attenuation of 
the cytosolic synthesis of proteins and activation of the proteasome to prevent the accumulation of mistargeted proteins.

To determine whether mistargeted mitochondrial proteins are responsible for proteasomal regulation, we utilized Pet $191_{\mathrm{FLAG}}$ and Mix $17_{\mathrm{FLAG}}$, which were partly mislocalized to the cytosol when ectopically expressed ${ }^{8}$ but remained largely soluble (Fig. 1i, Extended Data Fig. 5f, 7a, b). Proteins that formed aggregates were previously shown to inhibit the proteasome ${ }^{23}$. The steady-state levels of cellular proteins, including ribosomal and proteasomal subunits, rRNA levels and cytosolic translation were unchanged upon the Pet191 $1_{\mathrm{FLAG}}$ and Mix17 FLAG overexpression (Extended Data Fig. 7c-e). However, in the presence of mistargeted Pet191 $1_{\mathrm{FLAG}}$ or Mix17 $7_{\mathrm{FLAG}}$ proteasomal activity increased substantially (Fig. 3a, Extended Data Fig. 7f). Thus, mitochondrial protein mislocalization uncoupled protein degradation and protein synthesis effects.

Other mitochondrial proteins, Cox4 and Mdj1 (substrates of the TIM23 pathway) and their non-imported variants that lacked presequences (mCox4 and mMdj1), were overexpressed (Extended Data Fig. 7g-i). The overexpression of Cox4, but not Mdj1, led to a visible accumulation of a cytosolic precursor form (Extended Data Fig. 7g, h). Cox4, mCox4, and mMdj1 (despite its low abundance) stimulated the proteasome in contrast to fully imported Mdj1 (Fig. 3b). Non-mitochondrial model proteins, including mouse dihydrofolate reductase DHFR and its conformationally destabilized variant DHFRds, temperature sensitive $\mathrm{Ubc} \mathrm{ts}_{\mathrm{GFP}}{ }^{24}$ and native peroxisomal protein Pex22, were overexpressed and remained soluble (Extended Data Fig. 8a-c). They did not significantly affect proteasome activity (Extended Data Fig. 8d-g). To better mimic the stress caused by delayed mitochondrial import, we induced Mix17 in the presence of CCCP. The stimulatory effects of import inhibition and Mix 17 overexpression on proteasome activity were additive (Fig. 3c, Extended Data Fig. 8h). Thus, proteins that were delayed in their transport to organelles because of overexpression or 
the absence of mitochondrial targeting signals or chemical import inhibition stimulated proteasomal activity.

No proteasomal activity stimulation by Mix17 was observed in cells lacking $\operatorname{Irc} 25$ or Poc4 (Fig. 3d, Extended Data Fig. 9a, b). Indeed, proteasomal subunits were not upregulated (in contrast to Irc25 and Poc4; Fig. 1f, Supplementary Table 3) and the purified proteasome was not stimulated in vitro by Pet191 $1_{\mathrm{FLAG}}$ or Mix17 $7_{\mathrm{FLAG}}$ (Extended Data Fig. 9c). The $26 \mathrm{~S}$ proteasome is assembled from components, including the $20 \mathrm{~S}$ catalytic core and the $19 \mathrm{~S}$ regulatory particle ${ }^{10-12}$. Scl1 $1_{\mathrm{TAP}}$ (core subunit) and Rpn6 $6_{\mathrm{TAP}}$ (regulatory subunit) were used to purify the $20 \mathrm{~S}$ core (represented by Pre10) and the $26 \mathrm{~S}$ proteasome that comprised the core and regulatory particles (represented by Rpt1 and Rpt5) (Fig. 4a, b, Extended Data Fig. 9d). The proteasomal subunits were eluted more efficiently with Scl1 $1_{\mathrm{TAP}}$ and Rpn6 $6_{\mathrm{TAP}}$ upon Mix 17 overexpression (Fig. 4c, d). Thus, the stimulatory effect was associated with proteasomal assembly.

Interestingly, heat-shock conditions revealed a gain of stress resistance upon mitochondrial precursor appearance (Fig. 4e, f and Extended Data Fig. 10a). Interestingly, in the cells without Irc25 or Poc4, Mix17 $7_{\text {FLAG }}$ and Cox12 $2_{\text {FLAG }}$ exerted toxicity under temperature stress conditions (Fig. 4f). The induction of Pet191 $1_{\mathrm{FLAG}}$, Mix $17_{\mathrm{FLAG}}$, and Cox12 $2_{\mathrm{FLAG}}$, but not DHFR $_{\mathrm{FLAG}}$, in these cells led to a synthetic growth defect (Fig. 4g and Extended Data Fig. 10b). Cells without Poc1, Poc2, Ump1 or the proteasomal component Pre9 did not exhibit an increase in lethality (Fig. 4h). Thus, the response that was activated by protein mistargeting relied on proteasome assembly governed by the Irc25-Poc4 complex.

The mitochondrial protein import slowdown and precursor over-accumulation stress triggers processes that maintain cellular proteostasis. This includes the inhibition of protein synthesis and activation of the proteasome that originates from mistargeted proteins (Extended Data Fig. 10c). This unfolded protein response activated by protein mistargeting, 
(UPRam) exerts a protective effect on the cells. UPRam differs from UPRmt, another response pathway to compromised mitochondrial function present in higher Eukaryotes, because UPRmt acts by regulating the abundance of chaperones and proteases inside mitochondria ${ }^{25-27}$. Proteasomal activation and mild mitochondrial dysfunction have both been strongly implicated in the positive regulation of longevity ${ }^{28-30}$. The newly identified UPRam causally links defects in mitochondrial biogenesis with proteasomal activity, thus providing a possible explanation for the beneficial effects of mild mitochondrial dysfunction on ageing.

Online Content Methods, along with Extended Data display items, Source Data and Supplementary Information, are available in the online version of the paper; references unique to these sections appear only in the online paper. 
1 Chacinska, A., Koehler, C. M., Milenkovic, D., Lithgow, T. \& Pfanner, N. Importing mitochondrial proteins: machineries and mechanisms. Cell 138, 628-644 (2009).

2 Endo, T., Yamano, K. \& Kawano, S. Structural insight into the mitochondrial protein import system. Biochim Biophys Acta 1808, 955-970 (2011).

3 Neupert, W. \& Herrmann, J. M. Translocation of proteins into mitochondria. Annu Rev Biochem 76, 723-749 (2007).

4 van der Laan, M., Hutu, D. P. \& Rehling, P. On the mechanism of preprotein import by the mitochondrial presequence translocase. Biochim Biophys Acta 1803, 732-739 (2010).

5 Chacinska, A. et al. Essential role of Mia40 in import and assembly of mitochondrial intermembrane space proteins. EMBO J 23, 3735-3746 (2004).

6 Stojanovski, D. et al. Mitochondrial protein import: precursor oxidation in a ternary complex with disulfide carrier and sulfhydryl oxidase. J Cell Biol 183, 195-202 (2008).

7 Ong, S. E. et al. Stable isotope labeling by amino acids in cell culture, SILAC, as a simple and accurate approach to expression proteomics. Mol Cell Proteomics 1, 376386 (2002).

8 Bragoszewski, P., Gornicka, A., Sztolsztener, M. E. \& Chacinska, A. The ubiquitinproteasome system regulates mitochondrial intermembrane space proteins. Mol Cell Biol 33, 2136-2148 (2013).

9 Brodsky, J. L. Cleaning up: ER-associated degradation to the rescue. Cell 151, 11631167 (2012).

10 Ciechanover, A. Intracellular protein degradation: from a vague idea through the lysosome and the ubiquitin-proteasome system and onto human diseases and drug targeting. Biochim Biophys Acta 1824, 3-13 (2012).

11 Finley, D. Recognition and processing of ubiquitin-protein conjugates by the proteasome. Annu Rev Biochem 78, 477-513 (2009).

12 Goldberg, A. L. Protein degradation and protection against misfolded or damaged proteins. Nature 426, 895-899 (2003).

13 Bragoszewski P. et al. Retro-translocation of mitochondrial intermembrane space proteins. Proc. Natl Acad. Sci. U S A (2015), doi: 10.1073/pnas.1504615112.

14 Kusmierczyk, A. R., Kunjappu, M. J., Funakoshi, M. \& Hochstrasser, M. A multimeric assembly factor controls the formation of alternative $20 \mathrm{~S}$ proteasomes. Nat Struct Mol Biol 15, 237-244 (2008).

15 Le Tallec, B. et al. 20S proteasome assembly is orchestrated by two distinct pairs of chaperones in yeast and in mammals. Mol Cell 27, 660-674 (2007).

16 Hirano, Y. et al. Cooperation of multiple chaperones required for the assembly of mammalian 20S proteasomes. Mol Cell 24, 977-984 (2006).

17 Ramos, P. C., Hockendorff, J., Johnson, E. S., Varshavsky, A. \& Dohmen, R. J. Umplp is required for proper maturation of the $20 \mathrm{~S}$ proteasome and becomes its substrate upon completion of the assembly. Cell 92, 489-499 (1998).

18 Hanssum, A. et al. An inducible chaperone adapts proteasome assembly to stress. $\mathrm{Mol}$ Cell 55, 566-577 (2014).

19 Schubert, U. et al. Rapid degradation of a large fraction of newly synthesized proteins by proteasomes. Nature 404, 770-774 (2000).

20 Fischer, M. et al. Protein import and oxidative folding in the mitochondrial intermembrane space of intact mammalian cells. Mol Biol Cell 24, 2160-2170 (2013).

21 Frazier, A. E. et al. Pam16 has an essential role in the mitochondrial protein import motor. Nat Struct Mol Biol 11, 226-233 (2004). 
22 Chacinska, A. et al. Mitochondrial presequence translocase: switching between TOM tethering and motor recruitment involves Tim21 and Tim17. Cell 120, 817-829 (2005).

23 Bennett, E. J., Bence, N. F., Jayakumar, R. \& Kopito, R. R. Global impairment of the ubiquitin-proteasome system by nuclear or cytoplasmic protein aggregates precedes inclusion body formation. Mol Cell 17, 351-365 (2005).

24 Escusa-Toret, S., Vonk, W. I. \& Frydman, J. Spatial sequestration of misfolded proteins by a dynamic chaperone pathway enhances cellular fitness during stress. Nat Cell Biol 15, 1231-1243 (2013).

25 Haynes, C. M. \& Ron, D. The mitochondrial UPR - protecting organelle protein homeostasis. J Cell Sci 123, 3849-3855 (2010).

26 Zhao, Q. et al. A mitochondrial specific stress response in mammalian cells. EMBO J 21, 4411-4419 (2002).

27 Nargund, A. M., Pellegrino, M. W., Fiorese, C. J., Baker, B. M. \& Haynes, C. M. Mitochondrial import efficiency of ATFS-1 regulates mitochondrial UPR activation. Science 337, 587-590 (2012).

28 Vilchez, D. et al. RPN-6 determines C. elegans longevity under proteotoxic stress conditions. Nature 489, 263-268 (2012).

29 Durieux, J., Wolff, S. \& Dillin, A. The cell-non-autonomous nature of electron transport chain-mediated longevity. Cell 144, 79-91 (2011).

30 Houtkooper, R. H. et al. Mitonuclear protein imbalance as a conserved longevity mechanism. Nature 497, 451-457 (2013). 


\section{Figure Legends}

Figure 1| The MIA pathway import efficiency regulates protein synthesis and proteasomal activity. a, b, Distribution of transcripts and proteins based on the GO term. c, d, Northern analysis of RNA and ratio of $25 \mathrm{~S} / 18 \mathrm{~S}$ rRNAs in yeast grown in respiratory medium. Mean +/- SEM, n=3. e, Protein synthesis in cells grown in glycerol. f, Distribution of proteins based on GO term. Dashed lines; $p$-value $<0.05$ and fold-change $<-1.5$ and $>1.5$. g, Cellular proteins were analysed for ubiquitination. h, Proteasomal activity. Mean +/- SEM, $\mathrm{n}=7$ (caspase-), $\mathrm{n}=4$ (chymotrypsin-like activity). i, Cells were fractionated into total $(\mathrm{T})$, post-mitochondrial supernatant (S) and mitochondria (M). j, Proteasomal activity in cells grown at $24^{\circ} \mathrm{C}$. Mean $+/-$ SEM, $n=4$ (caspase-), $n=6$ (chymotrypsin-like activity). $\mathbf{c}, \mathbf{h}, \mathbf{j},{ }^{*} \mathrm{p}$ value $<0.05 ;{ }^{* *}$-value $<0.03 ;{ }^{* * *}$-value $<0.01$. WT, wild-type. c-e, g, i, Uncropped blots are in Supplementary Information 1.

Figure 2 Defects in the presequence import pathway modulate protein synthesis and proteasomal activity. a, b, Cells were treated for $30 \mathrm{~min}$ with CCCP (pulse) and chased without CCCP and analysed for protein content and proteasomal activity. Mean +/- SEM, $\mathrm{n}=6$. c, The pam18, pam16 and wild-type were analysed for protein content. d, The pam16-3 cells after $90 \mathrm{~min}$ shift to $37^{\circ} \mathrm{C}$ were fractionated. Total (T), post-mitochondrial supernatant (S) and mitochondria (M). e, Cells were analysed for ubiquitination. f, Proteasomal activity. Mean +/- SEM, n=3 (caspase-), n=5 (chymotrypsin-like activity). g, Protein synthesis in cells grown in glycerol. b, f, ${ }^{*}$ p-value $<0.05 ; * *$-value $<0.03 ; * * *$-value $<0.01$. WT, wild-type. a, c-e, g, Uncropped blots are in Supplementary Information 1.

Figure $3 \mid$ Mitochondrial precursor proteins stimulate proteasomal activity. a, Proteasomal activity upon expression of Pet $191_{\mathrm{FLAG}}$ or Mix $17_{\mathrm{FLAG}}$ at $24^{\circ} \mathrm{C}$. Mean $+/-\mathrm{SEM}$, $\mathrm{n}=6$. b, Proteasomal activity upon expression of mCox $4_{\mathrm{FLAG}}$ or $\operatorname{Cox} 4_{\mathrm{FLAG}}$ at $28^{\circ} \mathrm{C}$ and mMdj1 $1_{\mathrm{FLAG}}$ or $\mathrm{Mdj}_{\mathrm{FLAG}}$ at $24^{\circ} \mathrm{C}$. Mean $+/-\mathrm{SEM}, \mathrm{n}=5$. c, Proteasomal activity upon 
Mix17 $7_{\text {FAG }}$ expression and CCCP treatment. Mean $+/-$ SEM, $n=3$. d, Proteasomal activity in cells lacking $\operatorname{Irc} 25$ or Poc 4 upon expression of Pet191 $1_{\mathrm{FLAG}}$ or Mix $17_{\mathrm{FLAG}}$ at $24^{\circ} \mathrm{C}$. Mean $+/-$ SEM, n=3 (caspase-), n=4 (chymotrypsin- like activity). a-c, *p-value $<0.05 ; * *$ p-value $<$ $0.03 ; * *$ p-value $<0.01$. WT, wild-type.

Figure $4 \mid$ Mistargeted proteins protect cells against stress. a, b, Affinity purification via Scl1 $1_{\mathrm{TAP}}$ or Rpn6 $6_{\mathrm{TAP}} \mathbf{c}$, d, Affinity purification via $\mathrm{Scl1}$ TAP or Rpn6 $6_{\mathrm{TAP}}$ upon $6 \mathrm{~h}$ induction of Mix $17_{\mathrm{FLAG}}$ at $24^{\circ} \mathrm{C}$. Load, $5 \%$; Eluate, $100 \%$. The empty vector eluate was set to 1 . Mean $+/-$ SEM, $n=4(\mathbf{c}), n=5$ (d). e, f, Lethality upon overexpression of mitochondrial proteins. Mean +/- SEM, n=4 (e), n=3 (f). Mean lethality values of cells with empty vector: WT, 19\% (e) or WT, 9.54\%; $\Delta i r c 25,9.01 \% ; \Delta p o c 4,7.13 \%$ (f), were set to 1. g, Cells were subjected to consecutive 10-fold dilutions. h, Lethality of cells. Mean +/- SEM, $n=3$. Mean lethality values of cells with empty plasmid: $\Delta p o c 4,5.33 \% ; \Delta p o c 1,11.02 \% ; \Delta p o c 2,11.68 \% ; \Delta u m p 1,9.91 \%$; $\triangle p r e 9 \%, 10.74$, were set to $1 . \mathbf{c}-\mathbf{e}, \mathbf{f}, \mathbf{h}, *$ p-value $<0.05 ; * *$ p-value $<0.03, * * *$ p-value $<0.01$. WT, wild-type. a-d, Uncropped blots are in Supplementary Information 1. 
Supplementary Information is available in the online version of the paper.

\section{Acknowledgments}

We thank Aleksandra Fergin, Bettina Knapp and Drs Bernard Guiard, Wolfgang Voos, Michael Glickman, Agnieszka Gornicka, Adrianna Loniewska-Lwowska, and Tomasz Wegierski for materials, experimental assistance and discussions. Deposition of the data to the ProteomeXchange Consortium is supported by PRIDE Team, EBI. Research in the BW laboratory is supported by the Deutsche Forschungsgemeinschaft and the Excellence Initiative of the German Federal \& State Governments (EXC 294 BIOSS). Research in the AC laboratory was supported by Foundation for Polish Science - Welcome Programme cofinanced by the EU within the European Regional Development Fund (LW, MES, EJ), National Science Centre grants 2011/02/B/NZ2/01402 (LW, UT, AV) and 2013/11/B/NZ3/00974 (PC) and Ministerial Ideas Plus schema 000263 (EJ). LW and UT were also supported by National Science Centre grant 2013/08/T/NZ1/00770 and Swiss National Science Foundation postdoctoral fellowship (PP300P3-147899), respectively. PB was supported by the National Science Centre grant 2013/11/D/NZ1/02294.

\section{Author Contributions}

L.W., U.T., P.B., M.E.S., A.V., P.C., S.M., and E.J. performed biochemical experiments. P.B. and M.L. performed RNA-Seq and analyses. S.W. and S.O. performed the mass spectrometry measurements and analyses. A.C., B.W., M.K. and A.D. analysed and supervised the study. A.C and B.W. conceived the project. All authors interpreted the experiments. A.C. wrote the manuscript with the input of other authors.

\section{Author Information}

Reprints and permission information is available at www.nature.com/reprints. The authors declare no competing financial interests. RNA-Seq data have been submitted to the ArrayExpress database under accession number E-MTAB-3588. The mass spectrometry 
proteomics data have been deposited to the ProteomeXchange Consortium via the PRIDE partner repository with the dataset identifier PXD001495. Readers are welcome to comment on the online version of the paper. Correspondence and requests for materials should be addressed to A.C. (achacinska@,iimcb.gov.pl) or B.W. (bettina.warscheid@biologie.unifreiburg.de). 


\section{Methods}

Yeast strains. Yeast Saccharomyces cerevisiae strains are derivatives of YPH499 (MATa,

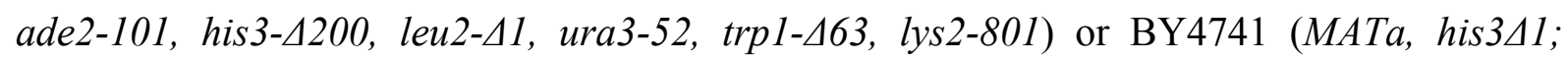
leu240; met1540; ura3 40 ). The temperature-sensitive mia40-4int (Fomp2-7int; 305), mia404 (YPH-fomp2-7; 176), mia40-3 (YPH-BG-fomp2-8; 178), mia40-F311E (660) and corresponding wild-type (398) strains were described previously ${ }^{5,6,8}$. The mia40-4int was generated by integration of the plasmid-borne mia40-4 allele into the genome ${ }^{6}$. This mutant showed a stronger decrease in the accumulation of intermembrane space proteins than mia40$4^{5,6,8}$, but due to a single genomic copy of mia40 was more suitable for SILAC. The SILAC strains are $\arg 8:: k a n M X 4$ derivatives of YPH499 (524) and mia40-4int (305) and are referred as to $\mathrm{WT}^{\mathrm{S}}$ (654) and mia40-4int $\mathrm{S}^{\mathrm{S}}$ (558; gift from Dr. Bernard Guiard). The pam16-1 (YPHBG-mia1-1; 733), pam16-3 (YPH-BG-mia1-3; 734), pam18-1 (YPH-BG-Mdj3-66; 739), tim17-4 (YPH-BG17-9d; 83), tim17-5 (YPH-BG17-21-7; 85) and corresponding wild-type $(738,524)$ strains were described previously ${ }^{21,22,31}$. Strains expressing PRE3 (843) or RPN6 (905) with a TAP tag and deletion strains of PRE9, POC1, POC2, IRC25, POC4, UMP1 in the BY4741 genetic background were purchased from Euroscarf. The strain expressing SCL1 with TAP tag was a gift from Dr. Michael Glickman (916). To rescue mia40-4int, the wildtype and mia40-4int yeast cells were transformed with a plasmid containing MIA40 under endogenous promoter (pGB8220; 85p). To overproduce Mia40, yeast cells were transformed with the TRP1-containing plasmid (pAC8-3, 97p) harbouring MIA40 (YKL195W) under control of the GAL10 promoter. The plasmid for $\mathrm{Ubc} \mathrm{ts}_{\mathrm{GFP}}$ overproduction was purchased from Add-gene (314p) ${ }^{24}$. To express PET191 (YJR034W), MIX17 (YMR002W), COX12 (YLR038C), POC1 (YLR199C), POC2 (YKL206C), IRC25 (YLR021W), POC4 (YPL144W), COX4 (YGL187C), MDJ1 (YFL016C), PEX22 (YAL055W) and DHFR encoding mouse dihydrofolate reductase or its destabilized version DHFRds in frame with the FLAG tag under 
control of the GAL10 promoter, yeast cells were transformed with $U R A 3$ - or $L E U 2$-containing pAG1 (53p), pAG2 (54p), pEJ1 (334p), pAG3 (55p), pPCh6 (320p), pPCh1 (315p), pMS126 (151p), pMS127 (152p), pMS120 (145p), pMS121 (146p), pUT9 (333p), pMS128 (162p), pMS119 (144p) plasmids. Mix17 (YMR002W) was previously known as Mic17 ${ }^{8,32,33}$. The mMdj1 and mCox4 constructs correspond to 17-511 and 25-155 amino acid residues of Mdj1 and Cox4, respectively. The sequence for DHFRds contains three destabilizing amino acid substitutions C7S, S42C, N49C (gift from Dr. Wolfgang Voos ${ }^{34,35}$ ).

Growth conditions The strains were grown on minimal synthetic medium $(0.67 \%$ [w/v] yeast nitrogen base, $0.079 \%[\mathrm{w} / \mathrm{v}] \mathrm{CSM}$ amino acid mix) containing respiratory carbon source (3\% $[\mathrm{v} / \mathrm{v}]$ glycerol supplemented with $0.05-0.2 \%[\mathrm{v} / \mathrm{v}]$ glucose $)$ or fermentable carbon source $(2 \%$ $[\mathrm{v} / \mathrm{v}]$ sucrose, $2 \%[\mathrm{v} / \mathrm{v}]$ galactose, $2 \%[\mathrm{v} / \mathrm{v}]$ glucose). To induce the GAL10 promoter for the expression of MIA40, cells were grown on minimal selective medium with $1.5 \%[\mathrm{v} / \mathrm{v}$ ] glycerol supplemented with $0.5 \%[\mathrm{v} / \mathrm{v}]$ galactose. To induce the GAL10 promoter for the expression of other proteins, cells were grown on minimal selective medium with $2 \%[\mathrm{v} / \mathrm{v}]$ galactose. In the experiments, in which Mia40 and Pet191 were simultaneously overproduced, cells were grown on minimal selective medium with $2 \%[\mathrm{v} / \mathrm{v}]$ galactose. The yeast strains were usually grown at permissive temperature $\left(19^{\circ} \mathrm{C}\right.$ or $\left.24^{\circ} \mathrm{C}\right)$ to the early logarithmic growth phase and analysed before or after a shift to a restrictive temperature $\left(37^{\circ} \mathrm{C}\right)$.

RNA-Seq. Wild-type and mia40-4int cells were grown at $19^{\circ} \mathrm{C}$ in the YPG $(1 \%$ [w/v] yeast extract, $2 \%[\mathrm{w} / \mathrm{v}]$ peptone, $3 \%[\mathrm{v} / \mathrm{v}]$ glycerol) medium to the mid-logarithmic phase $\left(\mathrm{OD}_{600}\right.$ of $\sim 0.65$ ) in three biological replicates per genotype. RNA was extracted with MagNALyser / MagNA Pure Compact RNA Isolation Kit (Roche) from frozen yeast preserved with RNAlater (Ambion). DNA was digested with TURBO DNA-free Kit (Life Technologies). The RNA quality and concentration were tested with Agilent 2100 Bioanalyzer and Qubit RNA BR Assay (Life Technologies). RNA was spiked with ERCC RNA Spike-In Mix (Life 
Technologies) and rRNA depleted with Ribo-Zero Gold rRNA Removal Kit (Illumina). RNAseq libraries were prepared with Ion Total RNA-Seq Kit v2 (Life technologies) with $2+10$ cycles amplification. Equimolar pool of barcoded libraries was used to prepare sequencing template with Ion PI Template OT2 200 Kit v3 (Life Technologies), followed by sequencing with Ion Proton on Ion PI v2 chip (Life Technologies). The reads were adapter trimmed and aligned using Torrent Suite and Partek Flow as suggested by Life Technologies. The reads were quality trimmed by Torrent Suite and resulting files were aligned to the Ensembl $S$. cerevisiae R64 reference genome (GCA_000146045.2) by Tophat $2^{36}$. Not aligned reads were submitted to the Bowtie $2^{37}$ alignment with the "very sensitive" setting. Alignments were combined and coordinate sorted with Samtools $^{38}$. Differential expression analysis was performed with Partek Genomics Suite (Partek). Transcripts were quantified to the Ensembl R64 GTF annotation file and resulting RPKM values were used for statistical analysis in Partek ANOVA (General Linear Model).

SILAC labelling and LC/MS sample preparation. Yeast strains of $\mathrm{WT}^{\mathrm{S}}$ and mia40-4int $\mathrm{S}^{\mathrm{S}}$ were grown at $19^{\circ} \mathrm{C}$ on respiratory minimal liquid medium $(0.67 \%[\mathrm{w} / \mathrm{v}]$ yeast nitrogen base, $0.068 \%[\mathrm{w} / \mathrm{v}] \mathrm{CSM}$ amino acid mix lacking arginine and lysine, $3 \%$ [v/v] glycerol, $0.02 \%$ [w/v] L-proline) supplemented with $18.6 \mathrm{mg} / 1\left[{ }^{13} \mathrm{C}_{6} /{ }^{15} \mathrm{~N}_{4}\right]$ L-arginine and $19.35 \mathrm{mg} / \mathrm{l}$ $\left[{ }^{13} \mathrm{C}_{6} /{ }^{15} \mathrm{~N}_{2}\right]$ L-lysine (Sigma-Aldrich) or non-labeled L-arginine and L-lysine. Three separate cultures were grown and differentially labeled using SILAC amino acids including a labelswitch. Following mixing of differentially SILAC-labeled $\mathrm{WT}^{\mathrm{S}}$ and mia40-4int ${ }^{\mathrm{S}}$ cells and cell lysis, proteins were acetone-precipitated and analysed using a gel-free and a gel-based approach. For the gel-free approach, proteins were redissolved in $60 \% \mathrm{MeOH} / 20 \mathrm{mM}$ $\mathrm{NH}_{4} \mathrm{HCO}_{3}(\mathrm{pH}$ 7.8) followed by reduction and alkylation of cysteines and tryptic digest as described $^{39}$. For the gel-based approach, proteins were resuspended in urea buffer $(7 \mathrm{M}$ urea/2 $\mathrm{M}$ thiourea/30 $\mathrm{mM}$ Tris- $\mathrm{HCl}, \mathrm{pH} 8.5)$ and separated (15 $\mu \mathrm{g}$ protein per replicate) on a 
4-12\% NuPAGE Bis-Tris gel. Lanes were cut into 15 slices, destained and washed as reported $^{40}$ followed by reduction and alkylation of cysteines ${ }^{39}$. Proteins were in-gel digested with trypsin and peptides reconstituted in $0.1 \%$ TFA.

LC/MS analysis. Peptides obtained by in-solution digestion were analysed in triplicates per biological replicate using an RSLCnano/LTQ-Orbitrap XL system (Thermo Scientific, Bremen, Germany) as described ${ }^{39}$ with the modification that peptides were separated with a 150 -min gradient ( $4-35 \%$ acetonitrile in $0.1 \%$ formic acid). Peptides derived from the gel were analysed on an RSLCnano/Orbitrap Elite system using a 45-min gradient and parameters as follows: survey scan range, $\mathrm{m} / \mathrm{z} 370-1,700$; resolution of $120,000(\mathrm{~m} / \mathrm{z} 400)$; top15 method (CID); automatic gain control and maximum fill time, $1 \times 10^{6}$ and $200 \mathrm{~ms}$ for the orbitrap, $5 \times 10^{3}$ and $150 \mathrm{~ms}$ for the linear ion trap; normalized collision energy, 35\%; activation q, 0.25; activation time, $10 \mathrm{~ms}$; dynamic exclusion, $45 \mathrm{~s}$.

MS data analysis. Data were processed using MaxQuant/Andromeda (version 1.3.0.5) and searched against the Saccharomyces Genome Database (www.yeastgenome.org). LC/MS data from mitochondrial samples were included to support peptide identifications. The database search was performed with default settings including deamination of asparagine and Pro6 as variable modifications. Protein identifications were based on at least one unique peptide. Mass tolerances for precursor and fragment ions were $6 \mathrm{ppm}$ and $0.5 \mathrm{Da}$, respectively. A false discovery rate of $1 \%$ was applied on peptide and protein level. SILAC ratios were calculated based on unique peptides using MaxQuant default settings and "match between runs". SILAC ratios for proteins were log-transformed and mean $\log _{10}$ ratios across all replicates and p-values (two-sided t-test) were determined. Protein groups exhibiting a posterior error probability $(\mathrm{PEP})<0.01$, a p-value $<0.05$ and a minimum fold change \pm 1.5 were classified as up- or downregulated in mia40-4int ${ }^{\mathrm{S}}$ cells. Variances of the mean $\log _{10}$ SILAC ratios were consistent across all three biological replicates yielding uniform data. 
Sample size, data analysis approach and the statistical test chosen fulfill the requirements for quantitative proteome analyses employing similar LC/MS instrumentation and methods. Statistical methods to determine sample size were not applied. The acquired data were normally distributed, thus meeting the assumption of the statistical test. All raw data and original MaxQuant result files have been deposited to the ProteomeXchange Consortium ${ }^{43}$ via the PRIDE partner repository ${ }^{44}$ with the dataset identifier PXD001495. GO term enrichment analysis of proteins classified as up- or downregulated was performed using the $\mathrm{BiNGO}^{45}$ plug-in 2.44 for Cytoscape $2.8^{46}$ and the yeast genome as background. Using the built-in Benjamini-Hochberg procedure, raw p-values calculated for GO enrichment analysis were corrected for multiple testing. GO terms with a corrected p-value $<0.05$ were considered enriched.

Proteasome activity assays. Proteasome activity assays were carried out as previously described $^{47}$ with few modifications. 20 OD $_{600}$ units of cells were shaken in lysis buffer (50 mM Tris- $\mathrm{HCl} \mathrm{pH}$ 7.4, 10 mM MgCl $2,10 \%$ glycerol, 2 mM ATP, 2 mM PMSF, 1 mM DTT) with glass beads (Sigma-Aldrich) for $10-20 \mathrm{~min}$ at $4^{\circ} \mathrm{C}$. After clarifying spin $(20,000 \mathrm{x}$ g, 15 min, $4^{\circ} \mathrm{C}$ ) protein concentration was determined by Bradford assay with bovine serum albumin as standard. Activity assays were performed in a final volume of $200 \mu 1$ of lysis buffer with $50 \mu \mathrm{g}$ of soluble total protein extracts in a 96-well plate by adding $100 \mu \mathrm{M}$ SucLeu-Leu-Val-Tyr-AMC peptide substrate (chymotrypsin-like activity; Bachem, I-1395) or $100 \mu \mathrm{M}$ Ac-NIe-Pro-NIe-Asp-AMC (caspase-like activity; Bachem, I-1850). Fluorescence (excitation wavelength $380 \mathrm{~nm}$, emission wavelength $460 \mathrm{~nm}$ ) was measured every 5 min for $1-2 \mathrm{~h}$ at $25^{\circ} \mathrm{C}$ using a microplate fluorometer (Infinite M1000, Tecan). For in vivo inhibition of proteasome activity, cells were grown as described previously ${ }^{8}$. Cultures were supplemented with either $75 \mu \mathrm{M}$ MG132 or DMSO. 
Stress assays. Cells were grown to the early logarithmic phase and expression of proteins was induced for $6 \mathrm{~h}$ at $24^{\circ} \mathrm{C}$ in minimal medium $(0.67 \%$ yeast nitrogen base, $0.077 \%$ amino acid supplement mixture) containing $2 \%[\mathrm{v} / \mathrm{v}]$ galactose. Only cultures with similar $\mathrm{OD}_{600}$ were compared for their viability after heat shock. One $\mathrm{OD}_{600}$ unit of yeast cells was washed with PBS (137 mM NaCl, $12 \mathrm{mM}$ phosphate, $2.7 \mathrm{mM} \mathrm{KCl}, \mathrm{pH}$ 7.4). Cells were stained with 3 $\mu \mathrm{g} / \mathrm{ml}$ propidium iodide in PBS for $15 \mathrm{~min}$ at room temperature in dark and analysed within 1 h by flow cytometry (FACSCalibur). 10,000 cells per each sample were measured.

Mitochondria procedures and cell fractionation. Yeast were usually grown on YPG medium. The yeast with overproduced Mia40 were grown on YPGal $(1 \%$ w/v] yeast extract, $2 \%[\mathrm{w} / \mathrm{v}]$ peptone, $2 \%[\mathrm{w} / \mathrm{v}]$ galactose). Mitochondria were isolated by differential centrifugation according to the standard method ${ }^{48}$. Mitochondria were solubilized in Laemmli buffer with $50 \mathrm{mM}$ DTT (reducing) or $50 \mathrm{mM}$ iodoacetamide (non-reducing conditions), and analysed by SDS-PAGE followed by Western blotting. $\left[{ }^{35} \mathrm{~S}\right]$ methionine radiolabeled precursors were prepared by in vitro transcription (mMESSAGE mMACHINE, Ambion) and translation (Rabbit Reticulocyte Lysate System, Promega) and imported into the isolated mitochondria as previously described ${ }^{6}$. Import experiments were performed in at least two different mitochondrial isolation (biological replicates) and repeated at least three times (technical replicates). For fractionation, yeast were grown on minimal medium with fermentable carbon source $\left(2 \%\right.$ glucose) to $\mathrm{OD}_{600} 0.5$, induced for 6 h or overnight by $2 \%$ galactose for overexpression of $M I A 40$ and $35 \mathrm{OD}_{600}$ units were fractionated by differential centrifugation ${ }^{8}$.

Mitochondrial precursor protein analysis. Yeast cells were grown in YPGal with addition of $0.2 \%$ glucose at $19^{\circ} \mathrm{C}$. Upon consumption of glucose yeast were grown for additional $2-3 \mathrm{~h}$ to $\mathrm{OD}_{600} 1.5-3$. Cultures were then supplemented with either $40 \mu \mathrm{M}$ carbonyl cyanide mchlorophenyl hydrazone (CCCP) or DMSO. After $1.5 \mathrm{~h}$ samples were analysed by SDS- 
PAGE and Western blotting. For pulse-chase experiments, upon consumption of glucose, yeast were grown for an additional $1 \mathrm{~h}$ to $\mathrm{OD}_{600}$ 1.1-1.3. Cultures were then supplemented with either $10 \mu \mathrm{M}$ CCCP or DMSO for pulse. For pulse-chase experiment with CCCP in combination with expression of Mix $17_{\mathrm{FLAG}}$ cells were grown at $24^{\circ} \mathrm{C}$ in minimal selective medium containing $2 \%[\mathrm{v} / \mathrm{v}]$ sucrose to logarithmic phase. Cells were washed and resuspended in YPGal medium and grown for $4 \mathrm{~h}$ at $24^{\circ} \mathrm{C}$. Cells were shifted for 15 min at $19^{\circ} \mathrm{C}$ before supplementing the culture with either $10 \mu \mathrm{M}$ CCCP or DMSO and were chased at $19^{\circ} \mathrm{C}$.

Aggregation assay. Cells were grown for $4 \mathrm{~h}$ at $28^{\circ} \mathrm{C}$ with either $75 \mu \mathrm{M}$ MG132 or the corresponding volume of $\mathrm{DMSO}^{8} .10 \mathrm{OD}_{600}$ unit of cells were shaken in lysis buffer $(30 \mathrm{mM}$ Tris- $\mathrm{HCl} \mathrm{pH}$ 7.4, $20 \mathrm{mM} \mathrm{KCl,} 5 \mathrm{mM}$ EDTA, $0.5 \mathrm{mM}$ PMSF, 0.5\% Trition X-100) with glass beads for $10 \mathrm{~min}$ at $4^{\circ} \mathrm{C}$. After clarifying centrifugation $\left(4,000 \mathrm{x} \mathrm{g}\right.$ for $\left.10 \mathrm{~min}, 4^{\circ} \mathrm{C}\right)$, total $(\mathrm{T})$ samples were separated into pellet (P) of aggregated proteins and supernatant (S) by ultracentrifugation for $1 \mathrm{~h}$ at $125,000 \mathrm{x}$ g. Total and supernatant fractions were precipitated by $10 \%$ trichloroacetic acid.

Affinity purifications. For purification of FLAG-tagged proteins cells were grown at $28^{\circ} \mathrm{C}$ in $3 \%[\mathrm{v} / \mathrm{v}]$ glycerol minimal medium with $0.5 \%[\mathrm{v} / \mathrm{v}]$ galactose. Cells $\left(100 \mathrm{U} \mathrm{OD}_{600}\right)$ were shaken in buffer A (20 mM Tris-HCl pH 7.4, $300 \mathrm{mM} \mathrm{NaCl,} 2 \mathrm{mM}$ PMSF) with glass beads for $20 \mathrm{~min}$ at $4{ }^{\circ} \mathrm{C}$. The solution was supplemented with $1 \%[\mathrm{w} / \mathrm{v}]$ digitonin and incubated for $15 \mathrm{~min}$ on ice. After clarifying centrifugation $\left(20,000 \times \mathrm{g}, 15 \mathrm{~min}, 4^{\circ} \mathrm{C}\right)$, supernatants were incubated with anti-FLAG M2 affinity gel (Sigma-Aldrich) at $4{ }^{\circ} \mathrm{C}$ for $1 \mathrm{~h}$. The column was washed with buffer A, followed by elution with $0.1 \mathrm{M}$ glycine $\mathrm{pH} 3.5$ for 5 min in RT. The $\mathrm{pH}$ of the elution fraction was adjusted to $\mathrm{pH}$ 7.4.

For proteasome complex purification, $100 \mathrm{OD}_{600}$ units of cells were shaken in buffer $\mathrm{B}(50$ $\mathrm{mM}$ Tris- $\mathrm{HCl} \mathrm{pH}$ 7.4, 10 mM MgCl $2,10 \%$ glycerol, 2 mM ATP, 2 mM PMSF, 1 mM DTT) 
with glass beads for $10 \mathrm{~min}$ at $4^{\circ} \mathrm{C}$. After clarifying centrifugation $\left(20,000 \mathrm{x} \mathrm{g}, 15 \mathrm{~min}, 4^{\circ} \mathrm{C}\right)$ supernatants were incubated with immunoglobulin G Sepharose (GE Healthcare) for $1 \mathrm{~h}$ at $4^{\circ} \mathrm{C}$. The column was washed and resuspended in $100 \mu \mathrm{l}$ of buffer B (for purified proteasome activity assay) or proteins were eluted by Laemmli buffer with $50 \mathrm{mM}$ DTT. Proteasome components co-purified with TAP-tagged proteins were quantified and the ratio of signals from cells with Mix17 versus empty plasmid was calculated and normalized to the efficiency of $\mathrm{Scl1} 1_{\mathrm{TAP}}$ or Rpn6 $6_{\mathrm{TAP}}$ recovery in the eluate.

Ribosome profile analysis. Yeast were grown on YPGal to early logarithmic phase and shifted to $37^{\circ} \mathrm{C}$. Cells were disrupted in lysis buffer $(40 \mathrm{mM}$ Tris- $\mathrm{HCl} \mathrm{pH} 7.4,100 \mathrm{mM} \mathrm{NaCl}$, $30 \mathrm{mM} \mathrm{MgCl}_{2}, 100 \mu \mathrm{g} / \mathrm{ml}$ cycloheximide, $300 \mu \mathrm{g} / \mathrm{ml}$ heparin, $1 \mathrm{mM}$ DTT, $0.5 \mathrm{mM}$ PMSF, 2 $\mu \mathrm{M}$ pepstatin $\mathrm{A}, 2 \mu \mathrm{g} / \mathrm{ml}$ chymostatin, $1 \mu \mathrm{M}$ leupeptin, $2 \mathrm{mM}$ benzamidie $\mathrm{HCl}$ and $5 \mu \mathrm{M}$ chymostatin) by shaking with glass beads followed by Triton X-100 addition to $0.2 \%$ and incubation for $15 \mathrm{~min}$ on ice. After clarifying spin $\left(20,000 \times \mathrm{g}, 10 \mathrm{~min}, 4^{\circ} \mathrm{C}\right)$, samples were separated on $10-50 \%[\mathrm{w} / \mathrm{v}]$ sucrose gradients in polysome buffer $(20 \mathrm{mM}$ Tris- $\mathrm{HCl} \mathrm{pH} 7.4$, $100 \mathrm{mM} \mathrm{NaCl}, 5 \mathrm{mM} \mathrm{MgCl} 2,100 \mu \mathrm{g} / \mathrm{ml}$ cycloheximide, $\left.2 \mathrm{mM} \mathrm{DTT} ; 222,000 \times \mathrm{g}, 2 \mathrm{~h}, 4^{\circ} \mathrm{C}\right)$. Gradients were fractionated with a continuous absorbance measurement at $254 \mathrm{~nm}$. The peak areas (volume $[\mathrm{ml}] \times$ absorbance $[\mathrm{mAU}])$ were quantified with Unicorn 5.2 (GE Healthcare).

Northern blot and qPCR assays. Total RNA was extracted from cells as described ${ }^{49}$. For Northern blot $5 \mu \mathrm{g}$ of RNA was separated on agarose or acrylamide denaturing gels, transferred to Hybond N+ (GE Healthcare) membrane and immobilized by the UVP CL-1000 crosslinker. Oligonucleotides used for RNA hybridizations (25S rRNA (007) 5'CTCCGCTTATTGATATGC; 18S rRNA (008) 5'-CATGGCTTAATCTTTGAGAC; 5.8S rRNA (017) 5'-GCGTTGTTCATCGATGC; 5S rRNA 5'-CTACTCGGTCAGGCTC) were labeled with $\left[\gamma^{32} \mathrm{P}\right] \mathrm{ATP}$ using T4 Polynucleotide Kinase (New England Biolabs). All Northern blot steps were performed using PerfectHyb Plus Hybridization Buffer (Sigma- 
Aldrich). Radioactive signals were detected by digital autoradiography. For qPCR analysis RNA extracts were treated with TURBO DNase (Ambion) and re-isolated. $1 \mu \mathrm{g}$ of RNA was reverse transcribed using SuperScript III First-Strand Synthesis SuperMix (Invitrogen) with $2.5 \mu \mathrm{M}$ oligo $(\mathrm{dT})_{20}$ and $1.8 \mu \mathrm{M}$ random hexamers as primers. Quantitative PCR reactions were performed using 7900HT Real-Time PCR (LifeTechnologies) and SensiFAST SYBR Hi-ROX Kit (Bioline) with standard protocol in triplicates. Standard curves were generated by the serial dilution of the pooled cDNA. To normalize nonspecific variations, the normalization factor was calculated as the geometric mean of transcript levels of 3 control genes, $A L G 9, F B A 1$ and $T U B 2$ that were selected on the basis of stability in transcriptomic and proteomic datasets and published observations ${ }^{50-52}$.

Statistical analysis. For statistical analysis, a two-tailed, paired t-test was used. For statistical analysis of SILAC, polysome profiles, Northern blots and qPCR a two-tailed, unpaired t-test, assuming unequal variance, was performed. A p-value $<0.05$ was considered significant. Proteasomal activity was calculated as a slope value and data are represented in a fold change compared to wild-type strain or wild-type containing the empty plasmid (with the exception for the pulse-chase experiments, in which the CCCP-treated samples were compared to the DMSO-treated control). Represented fold changes are the mean of fold changes obtained from independent biological replicates +/- standard error of the mean (SEM). ImageQuant was used for the quantification of Western-blotting results. The sample size used was estimated based on previous experiments and statistical tests were chosen based on published data with comparable methodology. Experiments have been replicated at least three times.

Miscellaneous. Volcano plot distribution of transcripts and proteins was based on the GO Slim terms provided by the Saccharomyces genome database (SGD). Protein extracts were prepared from amount of cells corresponding to $0.2-0.4 \mathrm{OD}_{600}$ units by alkaline lysis ${ }^{53}$ and resuspended in Laemmli buffer containing $50 \mathrm{mM}$ DTT. To assess protein synthesis, cells 
were grown in Met-free minimal medium before incubating with $\left[{ }^{35} \mathrm{~S}\right]$-labeled methionine and cysteine (EXPRESS; Perkin Elmer) that were added to a final concentration of $6 \mu \mathrm{Ci} / \mathrm{ml}$ for $20 \mathrm{~min}-2 \mathrm{~h}$. The samples were analysed by SDS-PAGE and digital autoradiography. Proteins were separated by SDS-PAGE on $15 \%, 12 \%$ or $10 \%$ gels. Primary antibodies were customraised in rabbits and individually controlled for specificity. Commercially available antibodies for mouse monoclonal anti-ubiquitin (SC-8017, Santa Cruz), anti-FLAG M2 (F1804, SigmaAldrich), rabbit polyclonal anti-Rpt5 (PW8245, Enzo Life Science), anti-Rpt1 (PW8255, Enzo Life Science), anti-alpha7/Pre10 (PW8110, Enzo Life Science) and anti-Hsp104 (ADI SPA 1040, Enzo Life Science) were used. Chemiluminescence protein signals were detected by use of X-ray films. Autoradiography signals were processed with ImageQuant (GE Healthcare). The images were processed digitally using Adobe Photoshop CS4. In some figures, nonrelevant gel parts were excised digitally. Protein concentration was determined using Roti-Quant (Carl Roth $\mathrm{GmbH}$ ) with bovine serum albumin as a standard. The nomenclature of proteins is according to the SGD.

31 Truscott, K. N. et al. A J-protein is an essential subunit of the presequence translocase-associated protein import motor of mitochondria. J Cell Biol 163, 707-713 (2003).

32 Böttinger, L. et al. In vivo evidence for cooperation of Mia40 and Erv1 in the oxidation of mitochondrial proteins. Mol Biol Cell 23, 3957-3969 (2012).

33 Pfanner, N. et al. Uniform nomenclature for the mitochondrial contact site and cristae organizing system. J Cell Biol 204, 1083-1086 (2014).

34 Vestweber, D. \& Schatz, G. Point mutations destabilizing a precursor protein enhance its post-translational import into mitochondria. EMBO J 7, 1147-1151 (1988).

35 Schreiner, B. et al. Role of the AAA protease Ymel in folding of proteins in the intermembrane space of mitochondria. Mol Biol Cell 23, 4335-4346 (2012).

36 Kim, D. et al. TopHat2: accurate alignment of transcriptomes in the presence of insertions, deletions and gene fusions. Genome Biol 14, R36 (2013).

37 Langmead, B. \& Salzberg, S. L. Fast gapped-read alignment with Bowtie 2. Nat Methods 9, 357-359 (2012).

38 Li, H. et al. The Sequence Alignment/Map format and SAMtools. Bioinformatics 25, 2078-2079 (2009).

39 Lytovchenko, O. et al. The INA complex facilitates assembly of the peripheral stalk of the mitochondrial F1Fo-ATP synthase. EMBO J 33, 1624-1638 (2014). 
40 Wiese, S. et al. Proteomics characterization of mouse kidney peroxisomes by tandem mass spectrometry and protein correlation profiling. Mol Cell Proteomics 6, 20452057(2007).

41 Cox, J. \& Mann, M. MaxQuant enables high peptide identification rates, individualized p.p.b.-range mass accuracies and proteome-wide protein quantification. Nat Biotechnol 26, 1367-1372 (2008).

42 Cox, J. et al. Andromeda: a peptide search engine integrated into the MaxQuant environment. J Proteome Res 10, 1794-1805 (2011).

43 Vizcaíno, J. A. et al. ProteomeXchange provides globally coordinated proteomics data submission and dissemination. Nat Biotechnol 32, 223-226 (2014).

44 Vizcaíno, J. A. et al. The PRoteomics IDEntifications (PRIDE) database and associated tools: status in 2013. Nucleic Acids Res 41, D1063-1069 (2013).

45 Maere, S., Heymans, K. \& Kuiper, M. BiNGO: a Cytoscape plugin to assess overrepresentation of gene ontology categories in biological networks. Bioinformatics 21, 3448-3449 (2005).

46 Shannon, P. et al. Cytoscape: a software environment for integrated models of biomolecular interaction networks. Genome Res 13, 2498-2504 (2003).

47 Kruegel, U. et al. Elevated proteasome capacity extends replicative lifespan in Saccharomyces cerevisiae. PLoS Genet 7, e1002253 (2011).

48 Meisinger, C., Pfanner, N. \& Truscott, K. N. Isolation of yeast mitochondria. Methods Mol Biol 313, 33-39 (2006).

49 Tollervey, D. \& Mattaj, I. W. Fungal small nuclear ribonucleoproteins share properties with plant and vertebrate U-snRNPs. EMBO J 6, 469-476 (1987).

50 Vandesompele, J. et al. Accurate normalization of real-time quantitative RT-PCR data by geometric averaging of multiple internal control genes. Genome Biol 3, RESEARCH0034 (2002).

51 Teste, M. A., Duquenne, M., Francois, J. M. \& Parrou, J. L. Validation of reference genes for quantitative expression analysis by real-time RT-PCR in Saccharomyces cerevisiae. BMC Mol Biol 10, 99 (2009).

52 Cankorur-Cetinkaya, A. et al. A novel strategy for selection and validation of reference genes in dynamic multidimensional experimental design in yeast. PLoS One 7, e38351 (2012).

53 Kushnirov, V. V. Rapid and reliable protein extraction from yeast. Yeast 16, 857-860 (2000). 


\section{Extended Data Figure Legends}

\section{Extended Data Figure 1 | Transcriptome and proteome analysis of WT and mia40-4int}

cells.

a, Distribution of transcripts quantified by RNA-Seq in WT and mia40-4int cells based on the GO term for translation provided by the Saccharomyces genome database. b, c, Distribution of transcripts and proteins based on the GO term for mitochondrial ribosome provided by the Saccharomyces genome database. d, SILAC-based strategy for the quantitative analysis of alterations in the proteome of yeast cells bearing the mia40-4int mutation. Derivatives of mia40-4int and WT (mia40-4int ${ }^{\mathrm{S}}$ and $\mathrm{WT}^{\mathrm{S}}$ ) were used for SILAC. The mia40-4int ${ }^{\mathrm{S}}$ cells grown at permissive temperature $19^{\circ} \mathrm{C}$ in heavy medium containing Lys 8 and $\operatorname{Arg} 10$ were mixed in equal ratio with $\mathrm{WT}^{\mathrm{S}}$ cells grown in the light medium containing Lys0 and Arg0 for set 1 (two biological replicates) or vice versa for set 2 (one additional biological replicate). e, The mia40-4int ${ }^{\mathrm{S}}$ strain and the parental mia40-4int strain exhibited similar temperaturesensitive phenotype. Both mutants and corresponding WT strains were subjected to consecutive 10-fold dilutions, spotted on YPD plates and grown at the indicated temperatures. f, The mia40-4int ${ }^{\mathrm{S}}$ strain showed no defect in the import of matrix-targeted Su9-DHFR as expected for mia40-4int. [ $\left.\mathrm{S}^{35}\right]$-labeled precursor of Su9-DHFR was incubated with isolated mitochondria from mia40-4int ${ }^{\mathrm{S}}$ and $\mathrm{WT}^{\mathrm{S}}$ strains for the indicated time points. g, Import of the MIA substrate, Tim9, was decreased in mia40-4int $\mathrm{S}^{\mathrm{S}}$ as expected for mia40-4int. $\left[\mathrm{S}^{35}\right]$-labeled precursor of Tim9 was incubated with the isolated mitochondria from mia40-4int ${ }^{\mathrm{S}}$ and $\mathrm{WT}^{\mathrm{S}}$ strains for the indicated time points. $\mathbf{f}, \mathbf{g}$, An excess of non-imported precursor was removed by the treatment of mitochondria with Proteinase K. Samples were analysed by reducing and non-reducing SDS-PAGE followed by autoradiography. $\mathbf{h}$, Sections of MS survey spectra of SILAC-encoded peptides for the MIA pathway substrates Cox19, Tim12 and Pet191 exhibiting decreased levels in mia40-4int ${ }^{\mathrm{S}}$ cells. MS survey spectra were acquired from the 
experimental set 1 as depicted in Extended Data Fig. 1d. i, Mitochondria were isolated from mia40-4int ${ }^{\mathrm{S}}$ and corresponding $\mathrm{WT}^{\mathrm{S}}$ grown at $19^{\circ} \mathrm{C}$ and analysed by Western blotting. $\mathbf{j}, \mathrm{WT}^{\mathrm{S}}$ and mia40-4int $t^{\mathrm{S}}$ yeast were grown to the stationary phase at $19^{\circ} \mathrm{C}$. Cellular extracts for mitochondrial proteins were analysed. The changes in protein abundance in mia40-4int $\mathrm{S}$ were as expected for the mia40-4int strain. k, Proteins quantified in three independent biological replicates were plotted according to their p-value $\left(\log _{10}\right)$ against the $\log _{10}$-transformed mia40$4 i n t^{S} / \mathrm{WT}^{\mathrm{S}}$ ratios. Proteins with a p-value $<0.05$ and a fold-change in protein abundance $>1.5$ or $<-1.5$ were considered up- and downregulated and are marked in green and red, respectively. The MIA pathway substrates are highlighted by enlarged circles. WT, wild-type; p, precursor; m, mature; *, unspecific band; IAA, iodoacetamide. f, g, i, j, Uncropped blots/gels are in Supplementary Information 1.

\section{Extended Data Figure $2 \mid$ Protein abundance in mia40-4int and mia40-4int ${ }^{s}$.}

a, Distribution of proteins quantified by SILAC-MS analysis of $\mathrm{WT}^{\mathrm{S}}$ and mia40-4int $\mathrm{S}$ cells based on the GO terms for cellular components provided by the Saccharomyces genome database. Subcellular localizations are shown for fractions of proteins with a significant 1.5fold change in abundance and a p-value $<0.05$ in the mia40-4int ${ }^{\mathrm{s}}$ cells. b, GO term enrichment analysis of proteins found to be significantly down- (top panel) or upregulated (bottom panel) in mia40-4int $\mathrm{S}$. c, $\mathrm{WT}^{\mathrm{S}}$ and mia40-4int $\mathrm{S}$ yeast were grown to the stationary phase at $19^{\circ} \mathrm{C}$. Cellular extracts were analysed for non-mitochondrial proteins. d, WT and mia40-4int yeast were grown in the respiratory medium to the logarithmic phase at $19^{\circ} \mathrm{C}$ and shifted for $6 \mathrm{~h}$ to $37^{\circ} \mathrm{C}$. Cellular extracts were analysed. No changes in protein abundance in mia40-4int in comparison to WT were observed. c, d, Uncropped blots are in Supplementary Information 1. e, f, Yeast were cultured in the full medium with galactose to early logarithmic phase and shifted for $3 \mathrm{~h}$ to $\left.37^{\circ} \mathrm{C}(\text { mia40-4int })^{\mathrm{s}}\right)$ (e) or $6 \mathrm{~h} 37^{\circ} \mathrm{C}$ (mia40-4int) (f). Cells were treated with $100 \mu \mathrm{g} / \mathrm{ml}$ cycloheximide for $10 \mathrm{~min}$. Yeast lysates were fractionated on a $10-$ 
$50 \%$ linear sucrose gradient and absorbance was monitored at $254 \mathrm{~nm}$. The retention of $40 \mathrm{~S}$, $60 \mathrm{~S}$ ribosomal subunits, monosomes $(80 \mathrm{~S})$ and polysomes is indicated. The monosomes versus polysomes ratio was quantified. Mean $+/-\mathrm{SEM}, \mathrm{n}=3$. WT, wild-type.

\section{Extended Data Figure 3 | Characterisation of the mia40-4int mutant.}

a, WT and mia40-4int were grown in respiratory medium and their growth was compared upon shift to the restrictive temperature of $37^{\circ} \mathrm{C} . \mathrm{OD}_{600}$ was measured at the indicated time points. b, The survival of WT and mia40-int grown to the logarithmic phase at $19^{\circ} \mathrm{C}$, heatshocked for $6 \mathrm{~h}$ at $37^{\circ} \mathrm{C}$ or heat-killed for $3 \mathrm{~min}$ at $80^{\circ} \mathrm{C}$ was assessed by propidium iodide (PI) staining. c, The mia40-4int and WT cells transformed or not with the plasmid encoding Mia40 were grown in respiratory medium at $19^{\circ} \mathrm{C}$ and shifted to $37^{\circ} \mathrm{C}$ for the indicated times. Protein levels were analysed. The mia40-4int-dependent defect in protein levels was complemented by MIA40. Uncropped blots are in Supplementary Information 1. d, mRNA levels of IRC25 or POC4 in mia40-4int $\mathrm{S}$, mia40-4int and corresponding WT. Cultures were grown in respiratory medium at $19^{\circ} \mathrm{C}$. The heat stress was conducted at $37^{\circ} \mathrm{C}$ for the indicated time. Primers used for qPCR: ALG9 5'-CACGGATAGTGGCTTTGGTGAACAATTAC, 5'TATGATTATCTGGCAGCAGGAAAGAACTTGGG; FBA1 5'ACGAAGGTCAAAATGCTTCCAT, 5'-TGGCACAGTGGTCAGAGTGTAAG; IRC25 5'CACTGGCAGGAAACCTAGGAAA，5'-CTCCCAACTTGGTAACCACTTGA; POC4 5'CTCTACCTGCAGACGATCGTTCT， 5'-GGGAATGGCGTAGTAATAACATGA; TUB2 5'- ATCTTGTCCCATTCCCACGTT, 5'-TTGCTGTGTTAATTCAGGGACAGT. Transcript levels of $A L G 9, F B A 1$ and $T U B 2$ were used for normalization. WT was set to 1. Mean +/- SEM, n=3. WT, wild-type.

\section{Extended Data Figure 4 | Proteasomal activity in mia40 mutants.}

a, WT was grown in respiratory medium at $19^{\circ} \mathrm{C}$ and shifted to $37^{\circ} \mathrm{C}$ for $6 \mathrm{~h}$. Where indicated, cell lysates were incubated with $50 \mu \mathrm{M}$ MG132 for 2 min prior to addition of 
caspase-like or chymotrypsin-like proteasome substrate. The activity was inhibited upon MG132 addition confirming the proteasomal specificity of the assay. $\mathbf{b}$, WT cells and cells deleted for POC1, POC2, IRC25, POC4, UMP1, and PRE9 were grown in respiratory medium to stationary phase at $24^{\circ} \mathrm{C}$. The proteasome caspase- and chymotrypsin-like activities were reduced upon the compromised proteasome demonstrating the specificity of the assay. Mean $+/-\mathrm{SEM}, \mathrm{n}=3 .{ }^{*}, \mathrm{p}$-value $<0.05$. c, Cells were grown in respiratory medium to logarithmic phase at $19^{\circ} \mathrm{C}$ and shifted to $37^{\circ} \mathrm{C}$ for $6 \mathrm{~h}$. Proteasomal activities were analysed over time. Left panel; mean of 7 biological replicates. Right panel; mean of 4 biological replicates. d, WT cells were grown at $24^{\circ} \mathrm{C}$ and were shifted for $6 \mathrm{~h}$ at $37^{\circ} \mathrm{C}$ or for $4 \mathrm{~h}$ at $42^{\circ} \mathrm{C}$. Proteasome activities and the levels of proteasomal subunits, Pre10, Rpt1 and Rpt5, were not changed. Mean $+/-$ SEM, $n=3$. e, Total protein extracts of plasmid-borne mia40 mutants were analysed by anti-ubiquitin immunoblotting and Coomassie staining. d, e, Uncropped blots/gels are in Supplementary Information 1. f, Proteasomal activity of WT and mia40 mutants. Mean +/- SEM, $\mathrm{n}=4 .{ }^{*}$, p-value $<0.05 ; * *$, p-value $<0.03$. WT, wild-type. RFU, relative fluorescent units.

\section{Extended Data Figure 5 | Characterization of cells that overproduce Mia40.}

a, Formation of a disulfide-bonded intermediate between Mia40 and Tim9 is accelerated in mitochondria with overproduced Mia40. Mitochondria were isolated from WT and Mia40 overproducing (Mia40个) strains and incubated with $\left[\mathrm{S}^{35}\right]$-labeled Tim9 precursor. When indicated iodoacetamide (IAA) was added as a control to block import. b, More efficient import of proteins in mitochondria with overproduced Mia40. Mitochondria from WT and Mia40个 strains were incubated with $\left[\mathrm{S}^{35}\right]$-labeled precursors. The samples were treated with proteinase $\mathrm{K}$ to remove non-imported proteins. c, Quantification of $\left[\mathrm{S}^{35}\right]$ radiolabeled Tim9 and Cox19 import. Mean +/- SEM, n=3. d, Cellular and mitochondrial protein levels were analysed in WT and Mia40个 strains by Western blotting. The overproduction of Mia40 did 
not significantly change the protein content. e, Quantification of Pet191 in mitochondria (M)

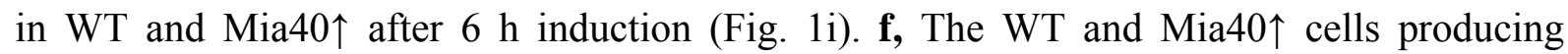
Pet $191_{\text {FLAG }}$ were grown in fermentable medium with $2 \%$ glucose at $24^{\circ} \mathrm{C}$ and shifted to galactose-containing medium for overnight induction. Protein levels in total (T), postmitochondrial supernatant (S) and mitochondria (M) were analysed. The mitochondrial localization (M) of Pet191 in WT and Mia40个 after overnight induction was quantified. WT, wild-type. a, b, d, f, Uncropped gels/blots are in Supplementary Information 1.

\section{Extended Data Figure 6 Characterization of mutants that affect the presequence TIM23 import pathway.}

a, The WT strain was grown to stationary phase at $19^{\circ} \mathrm{C}$ and treated with CCCP for $2 \mathrm{~h}$ to dissipate the electrochemical potential of the inner mitochondrial membrane. The CCCP treatment resulted in the accumulation of precursor proteins. $\mathbf{b}$, Representation of the pulsechase experiment. WT was treated for 30 min with CCCP (pulse) and chased in fresh medium without CCCP for 20 or 45 min for analysis. c, Non-processed precursor proteins accumulate in the tim 17 mutants. The tim17 mutants and corresponding WT were grown in fermentative medium to stationary phase at $19^{\circ} \mathrm{C}$, shifted to $37^{\circ} \mathrm{C}$ and analysed by Western blotting. $\mathbf{d}$, The tim 17-5 mutant was grown to stationary phase at $19^{\circ} \mathrm{C}$ and shifted to $37^{\circ} \mathrm{C}$ for $90 \mathrm{~min}$. The cells were fractionated and equal volumes of total $(\mathrm{T})$, post-mitochondrial supernatant $(\mathrm{S})$ and mitochondrial (M) fractions were analysed by Western blotting. Precursor proteins were localized in the cytosol together with cytosolic proteins (Rpl17 and Pgk1), in contrast to mature mitochondrial proteins (Cyc3, Tim23, Tom70). e, The pam16 and pam18 mutants were grown to logarithmic growth phase and shifted to restrictive temperature. Total protein content was analysed by Western blotting. No changes in protein levels were detected with the exception for a small decrease in the ribosomal proteins Rpl17 and Rpl24 was noticed. f, Ubiquitinated species are decreased in the tim17-4 and tim17-5 mutants. The tim 17 mutants 
and corresponding WT strain were grown in respiratory medium at $19^{\circ} \mathrm{C}$, shifted to $37^{\circ} \mathrm{C}$ and analysed by anti-ubiquitin immunoblotting. g, The pam16-1 and pam18-1 mutants were grown in respiratory medium at $19^{\circ} \mathrm{C}$ and shifted to $37^{\circ} \mathrm{C}$ for proteasomal activity assays. Mean of 3 biological replicates. h, The $\operatorname{tim} 17$ mutants and corresponding WT strain were grown in respiratory medium at $19^{\circ} \mathrm{C}$ and shifted to $37^{\circ} \mathrm{C}$ for proteasomal activity assays. Mean $+/$ - SEM, $n=3$ (caspase-like activity), $n=5$ (chymotrypsin-like activity). ${ }^{* * *}, \mathrm{p}$-value $<$ 0.01. i, Northern blot of rRNA and quantification. The pam16-3 and WT cells were grown in respiratory medium and shifted to $37^{\circ} \mathrm{C}$. Mean $+/-\mathrm{SEM}, \mathrm{n}=3$. j, Incorporation of $\left[{ }^{35} \mathrm{~S}\right]-$ labeled amino acids is decreased in tim 17 mutants compared to WT. Strains were grown in respiratory medium and shifted to $37^{\circ} \mathrm{C}$. Samples were taken after $1 \mathrm{~h}$ or $2 \mathrm{~h}$ of $\left[{ }^{35} \mathrm{~S}\right]$ labelling and analysed by SDS-PAGE and autoradiography. k, Representative gradient profiles of ribosomes in pam16-3 and WT and quantification of the monosome versus polysome fractions. Mean +/- SEM, n=3. *, p-value $<0.05$. Cells were grown to logarithmic phase, shifted to $37^{\circ} \mathrm{C}$ for $3 \mathrm{~h}$ and treated with $100 \mu \mathrm{g} / \mathrm{ml}$ cycloheximide for $10 \mathrm{~min}$. Lysates were fractionated on a $10-50 \%$ linear sucrose gradient and absorbance was monitored at $254 \mathrm{~nm}$. The monosomes versus polysomes ratio was quantified. WT, wild-type. RFU, relative fluorescent units. a, c-f, i, j, Uncropped blots/gels are in Supplementary Information 1.

\section{Extended Data Figure $7 \mid$ Translation and proteasomal activity in the cells overproducing mitochondrial proteins.}

a, Pet $191_{\mathrm{FLAG}}$ and Mix $17_{\mathrm{FLAG}}$ were expressed in WT cells at $24^{\circ} \mathrm{C}$. b, FLAG-tagged proteins were expressed in WT and when indicated cells were treated with MG132 for $4 \mathrm{~h}$. Fractions of total $(\mathrm{T})$, aggregates $(\mathrm{P})$ and soluble $(\mathrm{S})$ proteins were analysed by Western blotting. c, WT expressing Pet191 $1_{\mathrm{FLAG}}$ or Mix $17_{\mathrm{FLAG}}$ were grown at $24^{\circ} \mathrm{C}$ and analysed for total protein content by Western blotting. No changes in protein levels compared to WT were found, including ribosomal or proteasome subunits. d, Northern blot analysis of rRNA in cells 
expressing Mix17 $7_{\mathrm{FLAG}}$ and quantification. Mean $+/-$ SEM, $\mathrm{n}=3$. e, Mistargeted mitochondrial proteins do not alter the rate of translation. Incorporation of $\left[{ }^{35} \mathrm{~S}\right]$-labeled amino acids in WT expressing Pet $191_{\mathrm{FLAG}}$ or Mix17 $7_{\mathrm{FLAG}}$. The expression of FLAG-tagged proteins was induced for $6 \mathrm{~h}$ at $24^{\circ} \mathrm{C}$. Samples were taken $20 \mathrm{~min}$ after initiation of $\left[{ }^{35} \mathrm{~S}\right]$ labeling and analysed by SDS-PAGE and audioradiography. f, Expression of Pet191 $1_{\mathrm{FLAG}}$ or Mix17 $7_{\mathrm{FLAG}}$ stimulates proteasomal activity. Mean of 3 biological replicates. g, Cox $4_{\mathrm{FlAG}}$ with (pCox $4_{\mathrm{FLAG}}$ ) or without mitochondrial presequence $\left(\mathrm{mCox} 4_{\mathrm{FLAG}}\right)$ was expressed in WT. h, Mdj1 $1_{\mathrm{FLAG}}$ and mMdj $1_{\text {FLAG }}$ proteins were expressed in WT cells. The presence of FLAG-tagged proteins was confirmed by immunoblotting. i, WT expressing Mdj1 $1_{\mathrm{FLAG}}$ or $\mathrm{mMdj} 1_{\mathrm{FLAG}}$ were grown at $24^{\circ} \mathrm{C}$ and analysed for total protein content by Western blotting. No changes in protein levels compared to control were found, including ribosomal and proteasome subunits. WT, wildtype. RFU, relative fluorescent units. a-e, g-i, Uncropped blots are in Supplementary Information 1.

Extended Data Figure 8 Proteasomal activity in the cells overproducing nonmitochondrial proteins.

a, Expression of DHFR FLAG $_{\text {and DHFRds }}$ FLAG was induced at $24^{\circ} \mathrm{C}$ and Pex $22_{\mathrm{FLAG}}$ at $28^{\circ} \mathrm{C}$ in WT. The presence of FLAG-tagged proteins was confirmed by immunoblotting. $\mathbf{b}, \mathrm{Ubc} \mathrm{ts}_{\mathrm{GFP}}$ was induced in galactose and subsequently WT cells were shifted to glucose medium at $37^{\circ} \mathrm{C}$ to initiate unfolding. After indicated time points samples were analysed by Western blotting. c, FLAG-tagged proteins were expressed in WT for indicated time and the proteasome was inhibited with MG132 for $3 \mathrm{~h}$ if indicated. Fractions of total (T), aggregates (P) and soluble (S) proteins were analysed and no aggregation was observed. d, e, Proteasomal activity in WT expressing DHFR FLAG $_{\text {or DHFRds }}$ FLAG grown at $24^{\circ} \mathrm{C}$. Mean $+/-$ SEM $n=6$ (d). Mean of 6 biological replicates (e). f, WT expressing DHFR ${ }_{\mathrm{FLAG}}$ or DHFRds $\mathrm{FLAG}_{\mathrm{F}}$ were grown at $24^{\circ} \mathrm{C}$ and analysed for total protein content. No changes in protein levels were found compared to 
WT, including ribosomal and proteasome subunits. g, Proteasomal activity in WT expressing Pex $22_{\text {FLAG }}$ grown at $28^{\circ} \mathrm{C}$ and the abundance of proteins were not significantly changed. No significant change in proteasomal activity was detected upon expression of Ubc9ts $\mathrm{tsFP}_{\mathrm{GF}}$. Mean +/- SEM, $n=6$. h, The proteasomal stimulation by CCCP and Mix $17_{\text {FLAG }}$ is additive. WT cells with overproduced Mix17 $\mathrm{FLAG}$ were treated with CCCP to measure the chymotrypsin-like activity of the proteasome. In the case of Mix $17_{\mathrm{FLAG}}$ proteasomal stimulation was less efficient than stimulation reported for Mix $17_{\text {FLAG }}$ in Fig. $3 a$ due to change in experimental conditions imposed by the CCCP treatment. Mean +/- SEM, n=3. *, p-value $<0.05$; **, pvalue $<0.03$. Analysis of cellular protein content showed no difference in proteasome subunits (Rpt1, Rpt5) or ribosomal protein Rpl17. WT, wild-type. RFU, relative fluorescent units. a-c, f-h, Uncropped blots are in Supplementary Information 1.

Extended Data Figure 9| Auxiliary factors are required to stimulate proteasome by mitochondrial precursor proteins.

a, Proteasomal activity in WT expressing simultaneously either Poc $1_{\mathrm{FLAG}}$ and Poc $2_{\mathrm{Myc}}$ or Irc25 $5_{\mathrm{FLAG}}$ and Poc4 $4_{\mathrm{Myc}}$. Mean $+/-$ SEM, n=3. *, p-value $<0.05$. The overexpression of POC1 and POC2 or IRC25 and POC4 was induced from one plasmid. The overexpression of Irc25 2 FAG and Poc4 $4_{\text {Myc }}$ led to a small increase in the proteasomal activity in spite of the inability to detect these proteins likely due to tight regulation of their abundance (not shown). b, Proteasomal activity in cells lacking Irc25 or Poc4, expressing Mix17 $7_{\mathrm{FLAG}}$ or Pet191 1 FLAG and grown at $24^{\circ} \mathrm{C}$. Mean of 4 biological replicates. c, Affinity purification of the proteasome complex via Pre $3_{\mathrm{TAP}}$ from cells grown at $28^{\circ} \mathrm{C}$. Load, 5\%; Eluate, $100 \%$. Chymotrypsin-like activity of the proteasome bound to the column was measured. The specificity was checked by the treatment of the on-column fraction with proteasomal inhibitor MG132. Activity of the purified proteasome via Pre $3_{\mathrm{TAP}}$ was measured upon addition of purified Mix $17_{\mathrm{FLAG}}$ or Pet $191_{\mathrm{FLAG}}$ (for $7,5 \%$ of the on-column fraction). Mean $+/-$ SEM, $\mathrm{n}=3$. Uncropped blots are in 
Supplementary Information 1. d, Representation of the proteasome complex affinity purification. The subunits of proteasome are assembled into the $20 \mathrm{~S}$ catalytic core and the $19 \mathrm{~S}$ regulatory particle. The core and regulatory particles joint together to form the $26 \mathrm{~S}$ proteasome. Overexpression of an activator (i.e. Mix17) stimulates the 26S proteasome assembly. Thus, upon affinity purification via a TAP-tagged proteasome subunit, more other proteasomal subunits representing more assembled proteasomes are found in the eluate in the presence of an activator. WT, wild-type. RFU, relative fluorescent units.

\section{Extended Data Figure 10 The proteasome assembly factor Irc25-Poc4 is required to} protect cells against stress.

a, Representation of heat stress experiments. Cells overexpressing mitochondrial proteins were exposed to different heat shock conditions and subsequently subjected to lethality assessment (left panel). Cells were exposed to a gradual increase in temperature from $42^{\circ} \mathrm{C}$ to $53^{\circ} \mathrm{C}$ within $30 \mathrm{~min}$ or were incubated at $53^{\circ} \mathrm{C}$ for $30 \mathrm{~min}$. Mean lethality values of WT cells expressing empty plasmid increased with harsher stress conditions ( $9 \%$ for middle panel; $22 \%$ for right panel). The lethality of cells expressing empty plasmid was set to 1. Mean +/- SEM, $\mathrm{n}=5$ (middle panel), $\mathrm{n}=4$ (right panel). ${ }^{* *}, \mathrm{p}$-value $<0.03 ;{ }^{* * *}$, $\mathrm{p}$-value $<0.01 . \mathbf{b}, \mathrm{WT}$ or cells deleted for the IRC25 or POC4 genes and overproducing Pet191 $1_{\mathrm{FLAG}}$ or Cox $12_{\mathrm{FLAG}}$ protein were cultured on agar plates with sucrose. Consecutive 10-fold dilutions of cells were spotted on selective medium plates with either glucose or galactose. Cells were grown at the indicated temperatures. c, Model for cellular responses activated by the mitochondrial protein import and precursor over-accumulation stress. WT, wild-type. 


\section{Supplementary Table Legend}

\section{Supplementary Table 1 | RNA-Seq analysis of the mia40-4int mutant versus wild-type}

strain.

The MIA pathway is essential for life, thus only conditional mutants of its components Mia40 and Erv1 are available. The mia40 temperature-sensitive mutants, including mia40-4int, show the defect in the import of proteins into the IMS and are suitable for temperature manipulations to regulate the strength of defects ${ }^{5,6}$. Wild-type and mia40-4int cells were grown under permissive conditions at $19^{\circ} \mathrm{C}$ in YPG medium to mid-logarithmic phase $\left(\mathrm{OD}_{600}\right.$ of $\sim 0.65)$. Three biological replicates per genotype were analyzed. The RNA was prepared by extraction with the MagNA Lyser Instrument followed by ERCC Controls spike-in and rRNA depletion. The Ion Torrent directional RNA-Seq libraries were constructed according to manufacturer's instructions. Each library had a different barcode assigned. The amplified cDNA libraries were mixed equimolarly and sequenced on Ion Proton Sequencer during two runs. Reads were quality-trimmed by Torrent Suite with default parameters. Resulting files were aligned to the Ensembl S. cerevisiae R64 (GCA_000146045.2) reference genome by Tophat 2 and reads that were not aligned were submitted to the Bowtie2 alignment with "very sensitive" option selected. The alignment was conducted using Partek Flow and mRNA was quantified in Partek Genomics Suite. All identified transcripts are included in the table. The transcripts are sorted alphabetically starting with protein-coding genes. Locus systematic names, gene names and brief gene descriptions were extracted from the SGD. Differential expression analysis was done in Partek Genomics Suite using Partek ANOVA (General Linear Model) and data are presented in columns labeled "Data determined across all replicates". The other columns contain number of reads values and RPKM (Reads Per Kilobase of exon per Million mapped reads) values for each sample, quantified to the Ensembl R64 gene transfer format (GTF) annotation by Partek Genomics Suite. 506 genes 
were found differentially expressed (with p-value $<0.05$; Partek Genomics Suite) of which 190 were upregulated (with fold change $>1.5$ ) and 316 downregulated (with fold change $<$ 1.5) in mia40-4int. n.def., not defined.

\section{Supplementary Table 2 | SILAC-based proteomics analysis of mia40-4int ${ }^{\mathrm{S}}$ mutant versus}

\section{wild-type.}

Wild-type $^{\mathrm{S}}$ and mia40-4int ${ }^{\mathrm{S}}$ were grown in permissive conditions at $19^{\circ} \mathrm{C}$ in respiratory medium to assess the consequences of stress caused by a mild defect in the import of mitochondrial proteins. Equal amounts of differentially SILAC-labeled mia40-4int ${ }^{\mathrm{S}}$ and $\mathrm{WT}^{\mathrm{S}}$ cells were mixed, lysed and subjected to both gel-based and gel-free LC/MS analyses. Mass spectrometric raw data from three independent biological replicates were processed using the MaxQuant/Andromeda software (version 1.3.0.5) and searched against all entries in the Saccharomyces Genome Database (SGD). To assist in protein identification, MS/MS data from purified mitochondria obtained in gel-free LC/MS analyses $(n=3)$ were included for the database search. Proteins listed were identified with a false discovery rate of $<1 \%$ and at least one unique peptide across all replicates. Proteins sharing the same set of peptides are grouped together by MaxQuant and reported as single protein group. The protein exhibiting highest sequence coverage within a protein group is reported as first entry. Ordered locus names (OLNs), the corresponding gene names and protein descriptions were extracted from the SGD. OLNs and UniProt identifiers (ID) are provided as hyperlinks allowing for direct accession to the corresponding entry in the SGD and UniProt database, respectively. Relative protein quantification was based on at least one SILAC peptide pair; only unique peptides were considered. SILAC ratios were $\log$-transformed and mean $\log _{10}$ ratios across all experiments as well as p-values (two-tailed, unpaired t-test) were calculated. Proteins are sorted according to the sequence coverage starting with the highest value. PEP, posterior error probability; n.def., not defined. 
Supplementary Table 3 | Proteins quantified in SILAC-based proteomics in at least two biological replicates.

Data in this table are based on proteins listed in Supplementary Table 2. Proteins listed have been quantified in at least two independent biological replicates. Listed proteins are sorted according to their fold change. Proteins exhibiting a fold change $>1.5$ or $<-1.5$ and a p-value $<0.05$ (two-tailed, unpaired t-test) are marked in green and red, respectively. PEP, posterior error probability; n.def., not defined. 

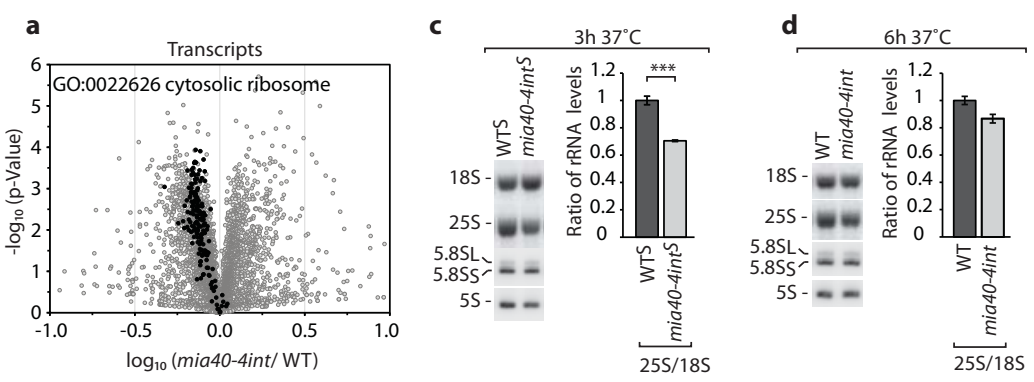

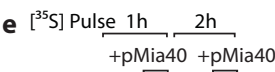

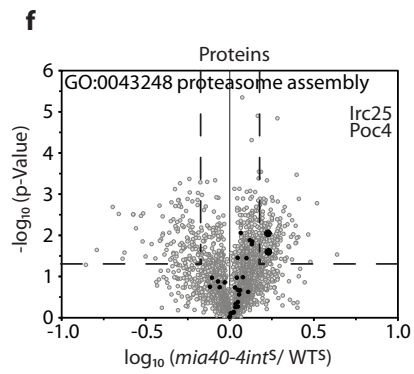

b

$\begin{array}{llll}\text { g } 1 \mathrm{~h} & 3 \mathrm{~h} & 6 \mathrm{~h} & 6 \mathrm{~h} 37^{\circ} \mathrm{C} \\ 19^{\circ} \mathrm{C} & 37^{\circ} \mathrm{C} & 37^{\circ} \mathrm{C} & 37^{\circ} \mathrm{C}\end{array}$
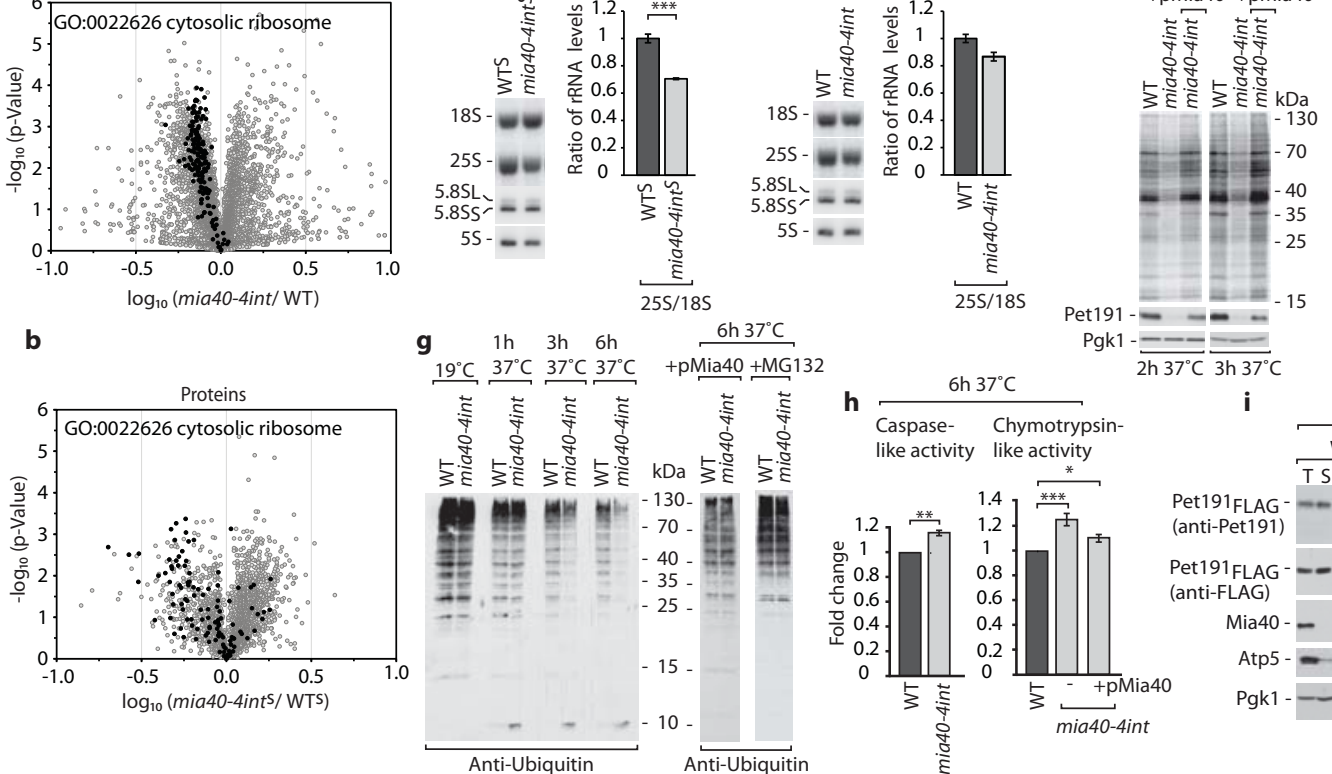

$37^{\circ} \mathrm{C} 3 \mathrm{~h} 37^{\circ} \mathrm{C}$

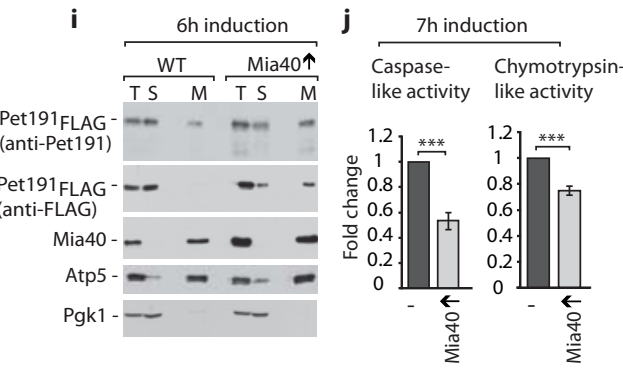

Figure 1 Wrobel, Topf et al - revised 3 


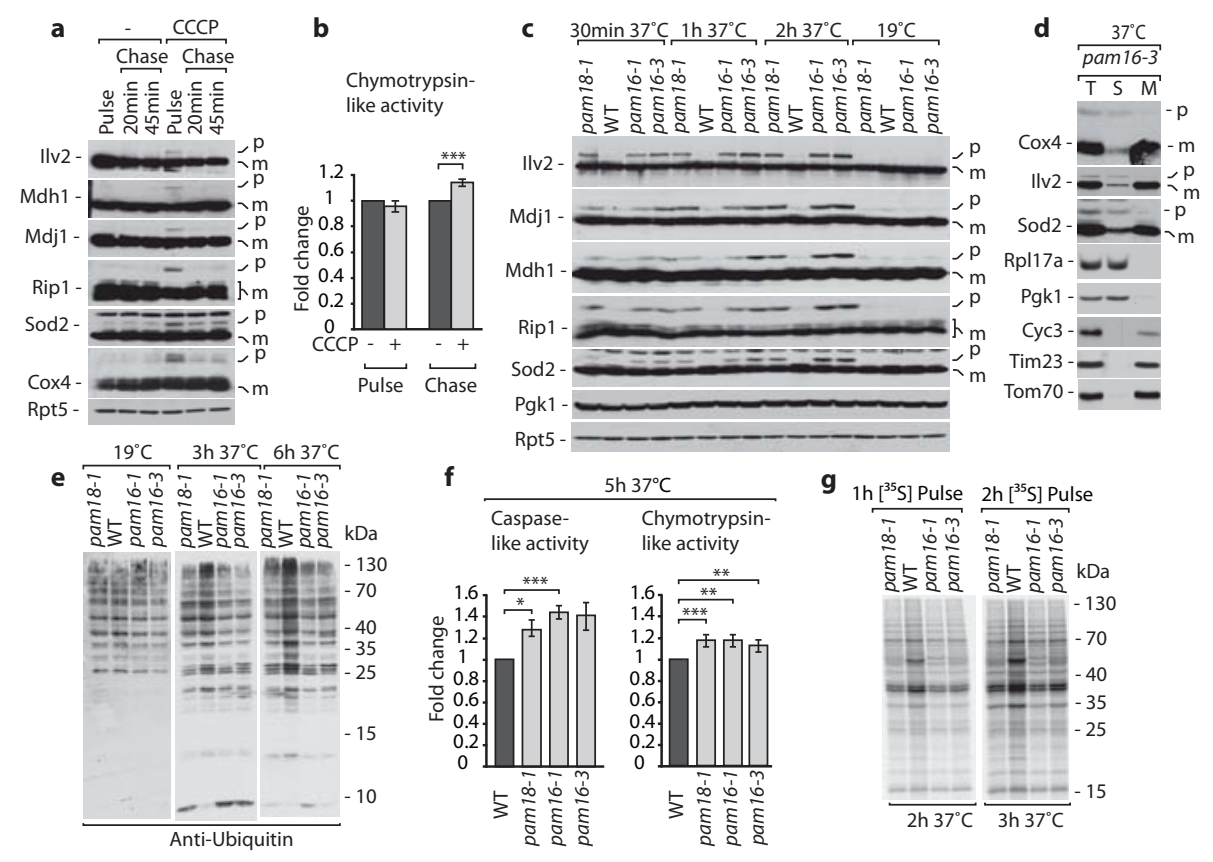

Figure 2 Wrobel, Topf et al - revised 3 


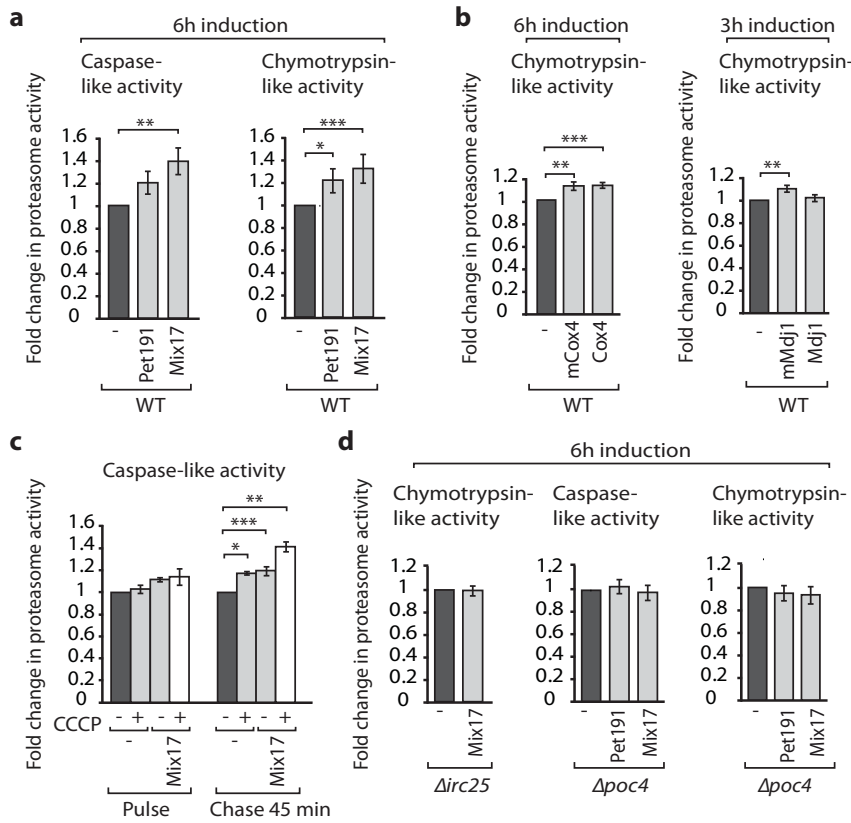

Figure 3 Wrobel, Topf et al - revised 3 

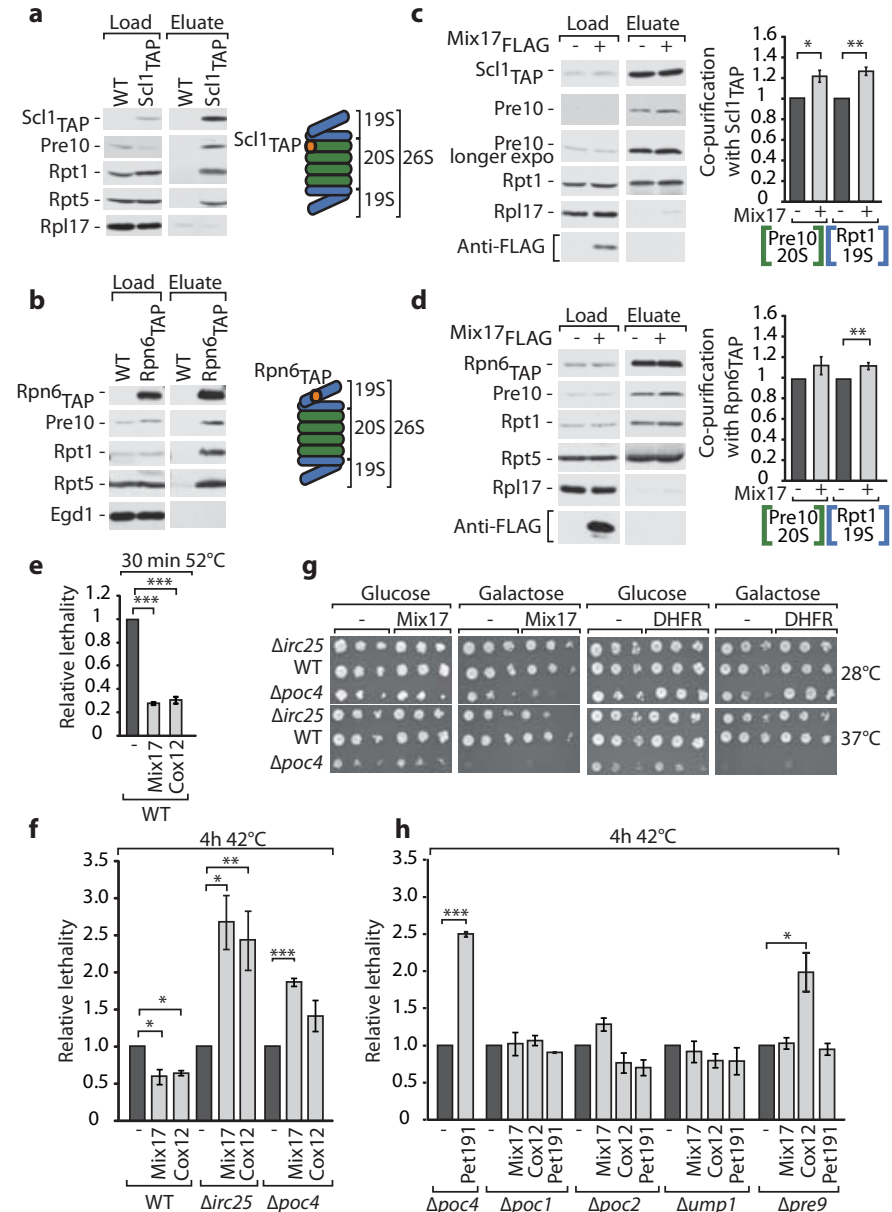

Figure 4 Wrobel, Topf et al - revised 3 


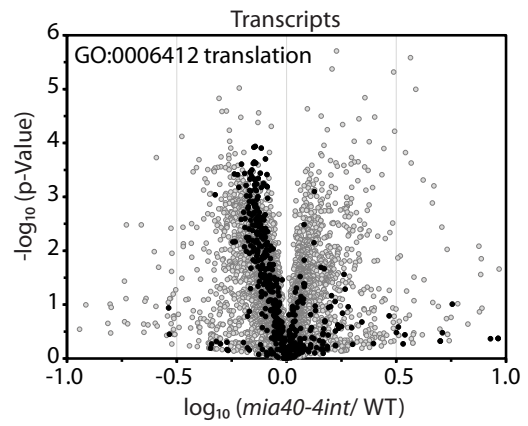

b

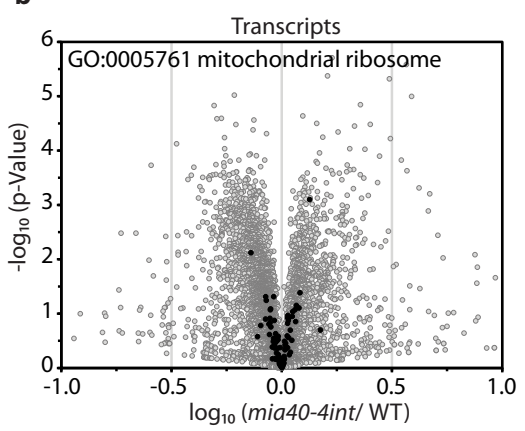

c

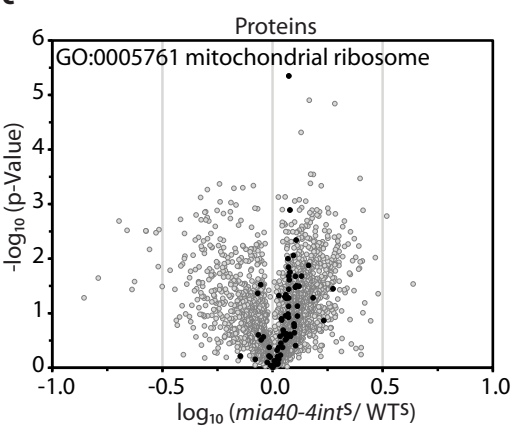

h

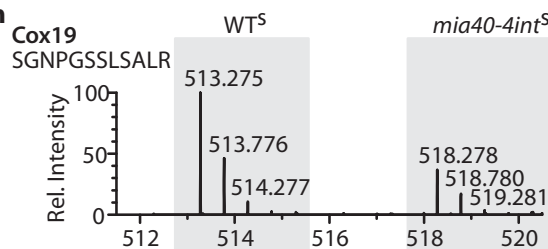

Tim12

SFFLNSLR 594.306

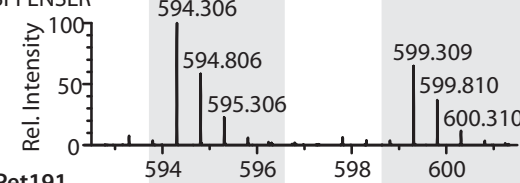

Tim9 -

g

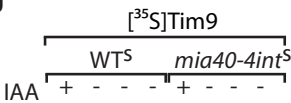
Time (min) 273 927273927 kDa Time (min) $27327273927-70$ 9-Mia40

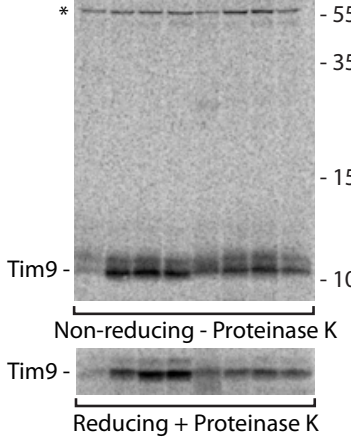$$
\text { Pet191 }
$$

DLPELCIAQMK

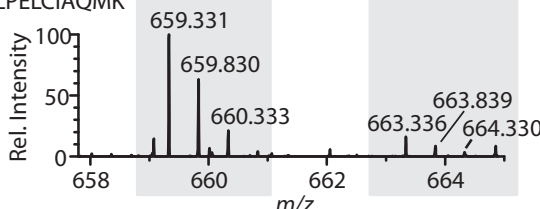

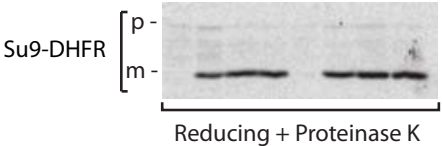

$$
\text { j } \quad \frac{W T^{S} \text { mia40-4int }}{\mathrm{S}^{\mathrm{N}}}
$$

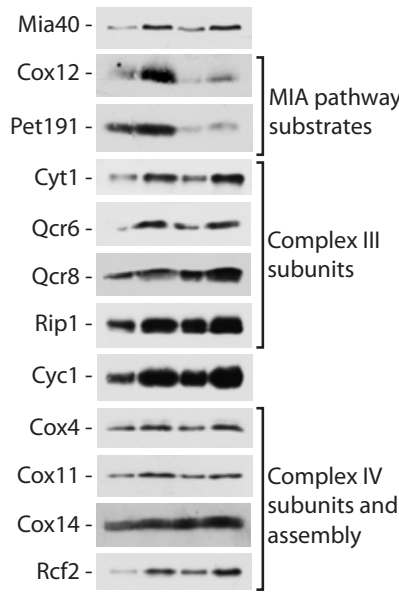

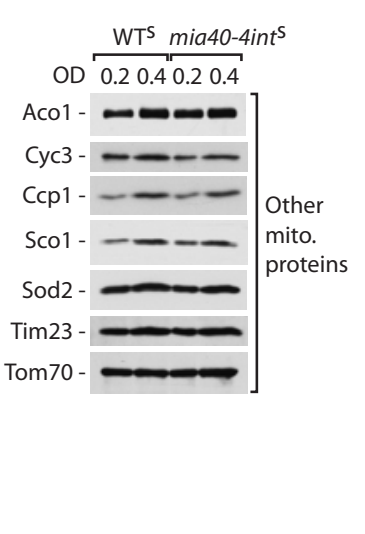

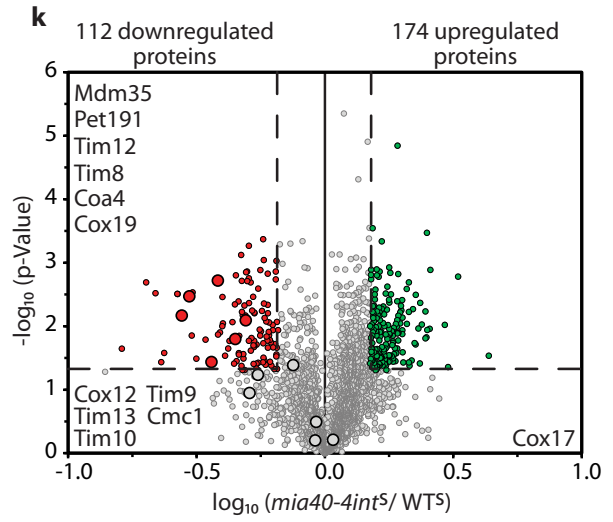

Extended Data Figure 1 Wrobel, Topf et al - revised 3 
a

Proteins downregulated in mia40-4int ${ }^{S}$ cells Mitochondria

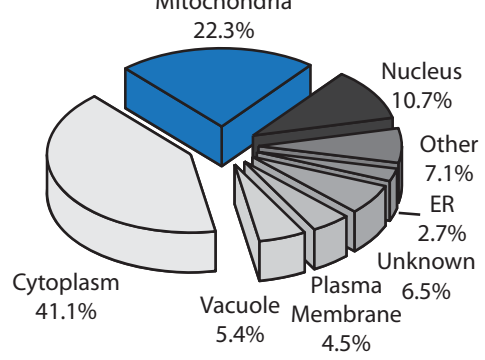

Proteins upregulated in mia40-4int ${ }^{S}$ cells

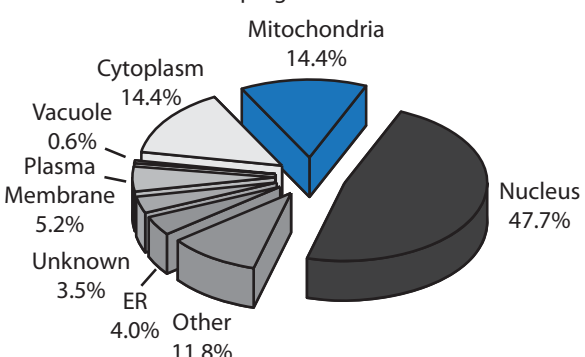

$11.8 \%$

C

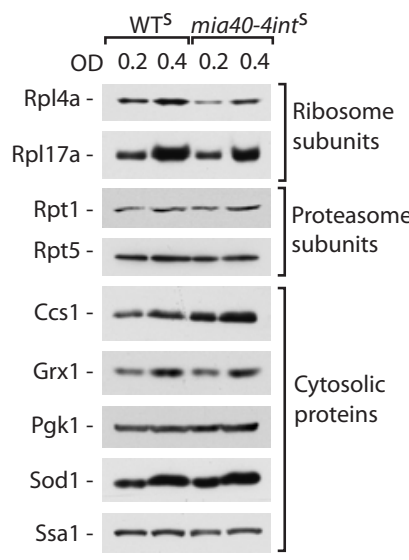

d

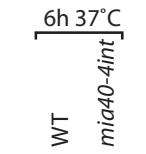

$0.4 \quad 0.4$

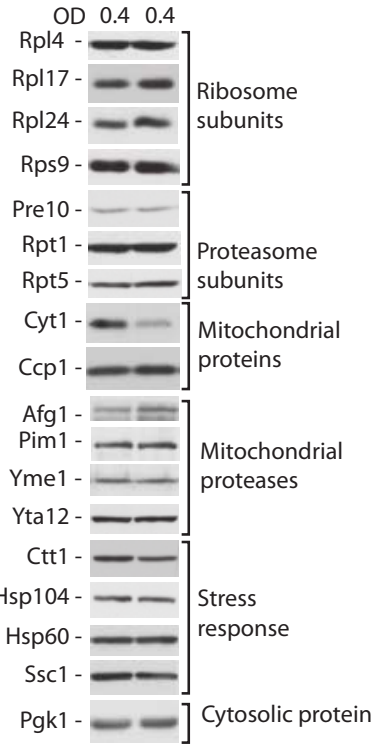

b
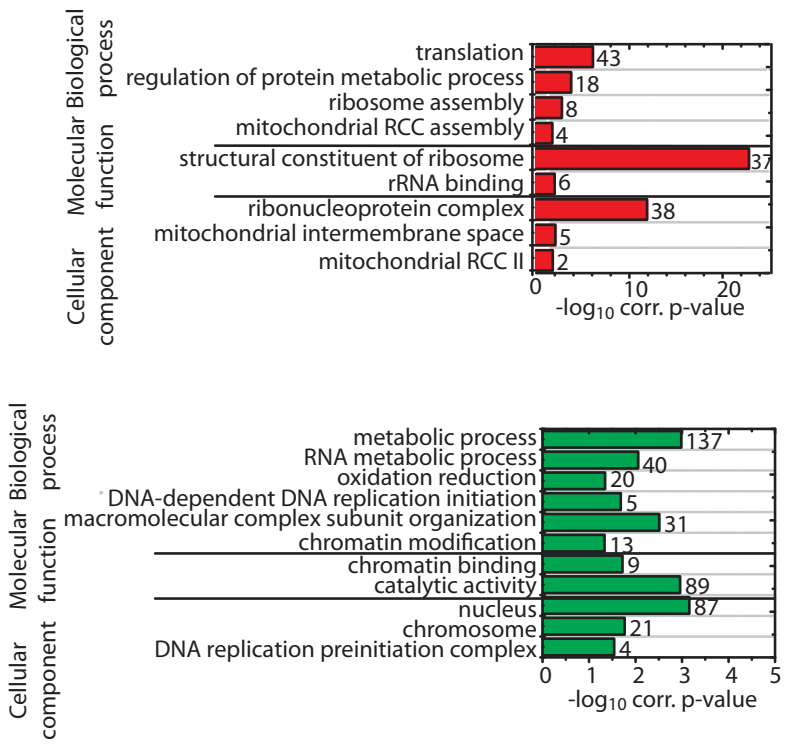

e $3 \mathrm{~h} 37^{\circ} \mathrm{C}$
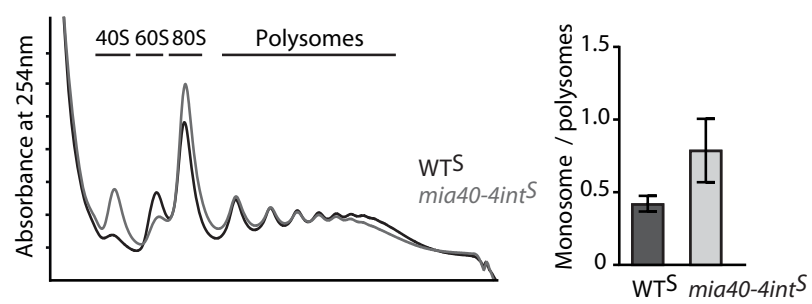

f

$6 \mathrm{~h} 37^{\circ} \mathrm{C}$
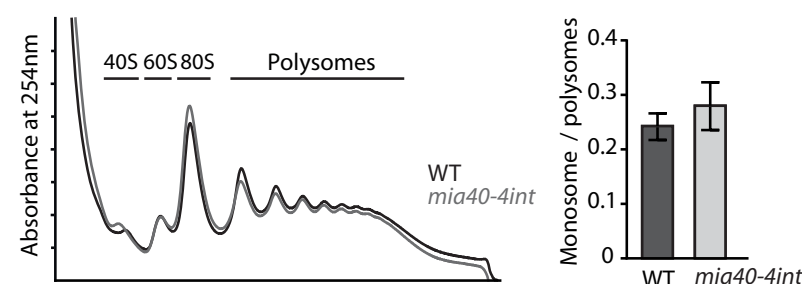

Extended Data Figure 2 Wrobel, Topf et al - revised 3 
a

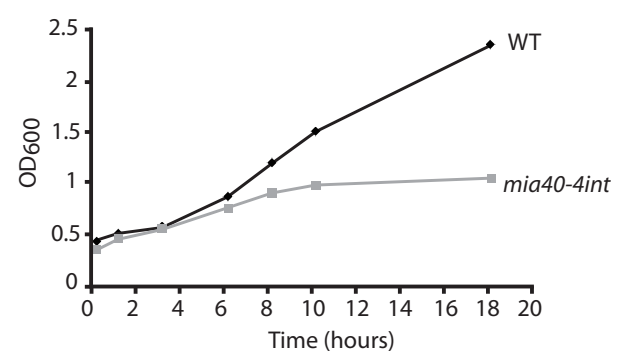

c

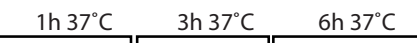

+ pMia40 +pMia40+pMia40

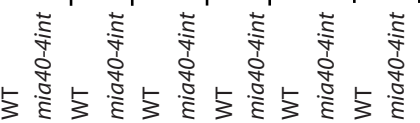

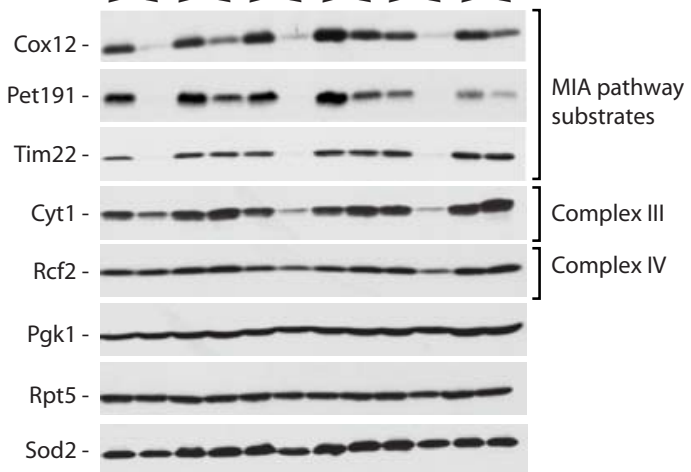

b

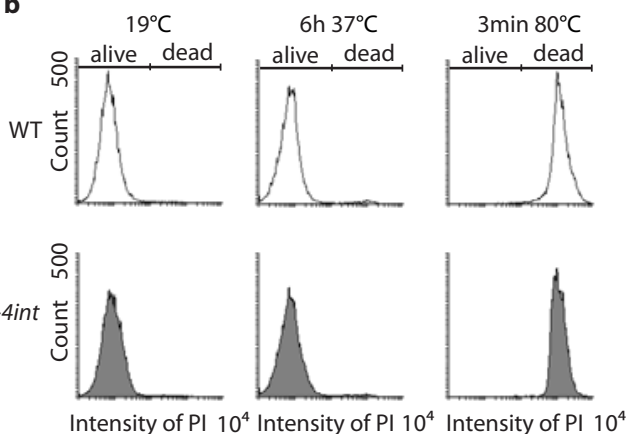

d

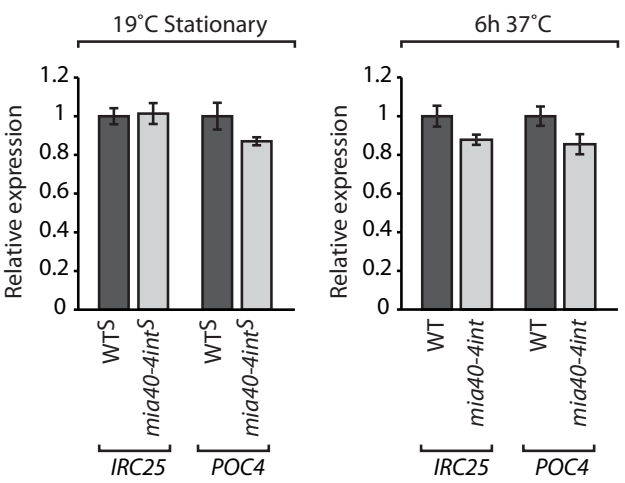

Extended Data Figure 3 Wrobel, Topf et al - revised 3 


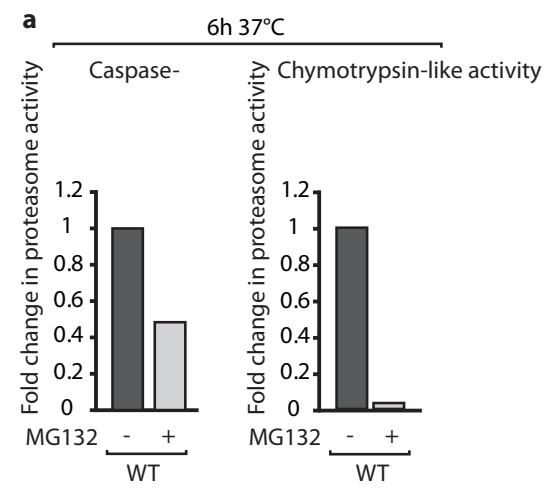

b
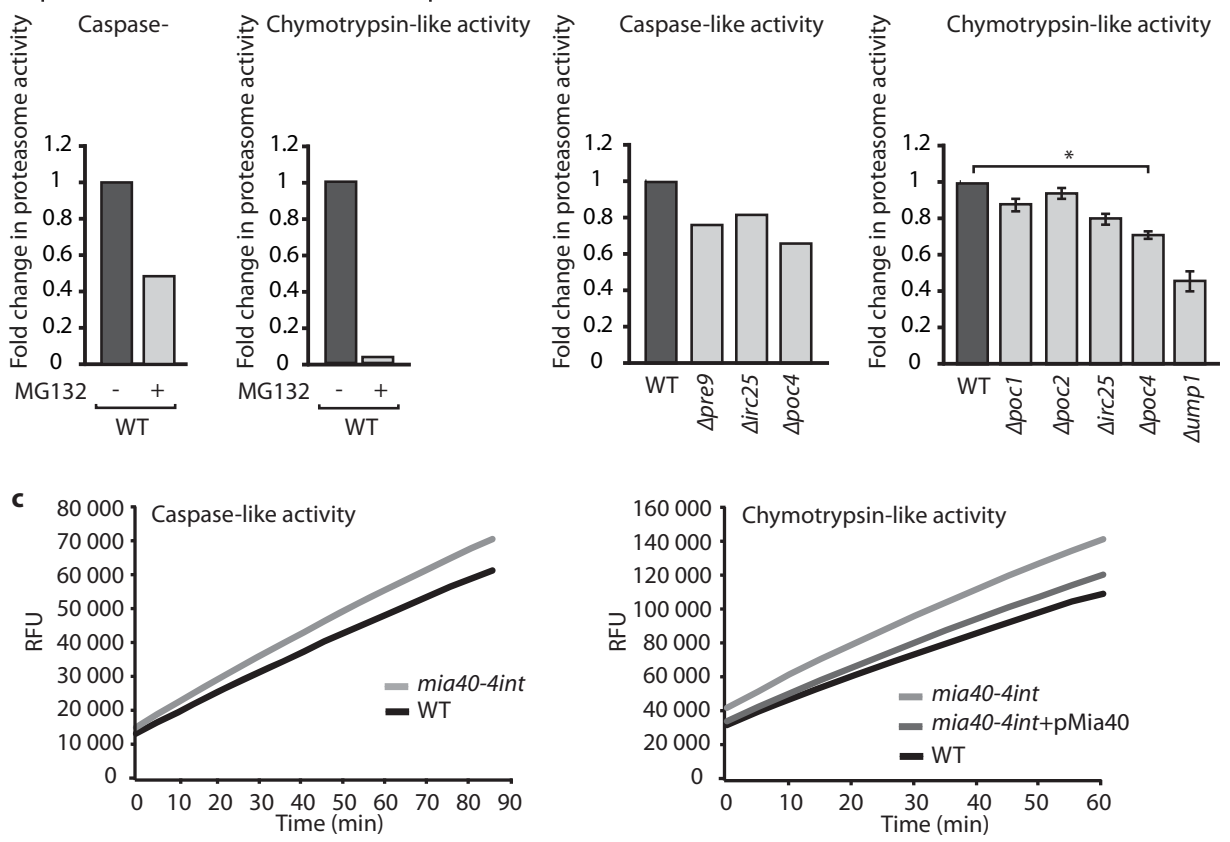

d
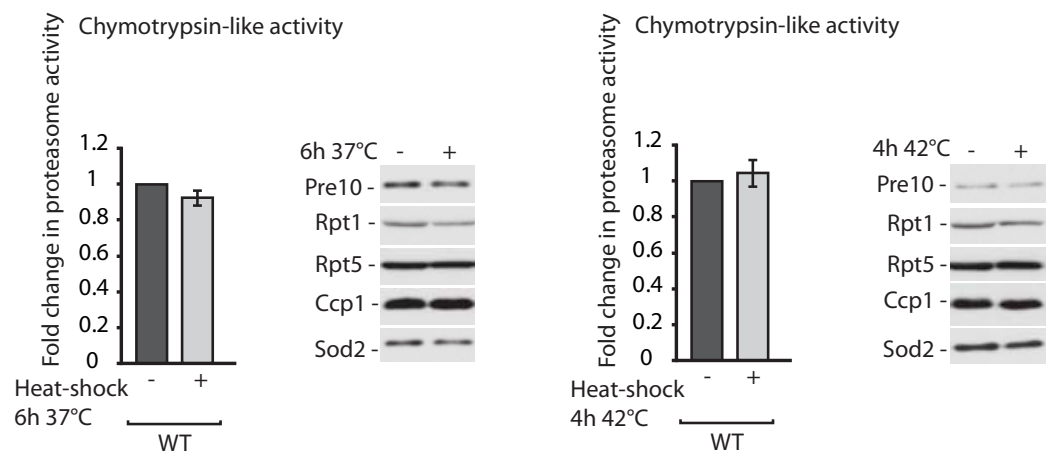

e
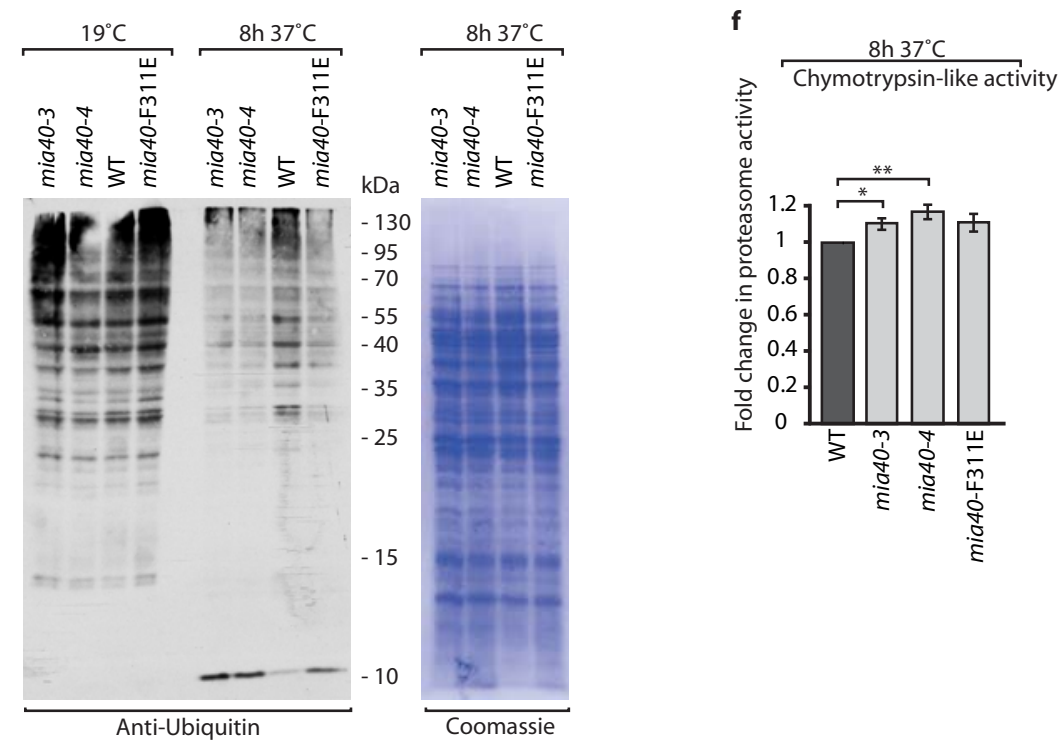

Extended Data Figure 4 Wrobel, Topf et al - revised 3 
a

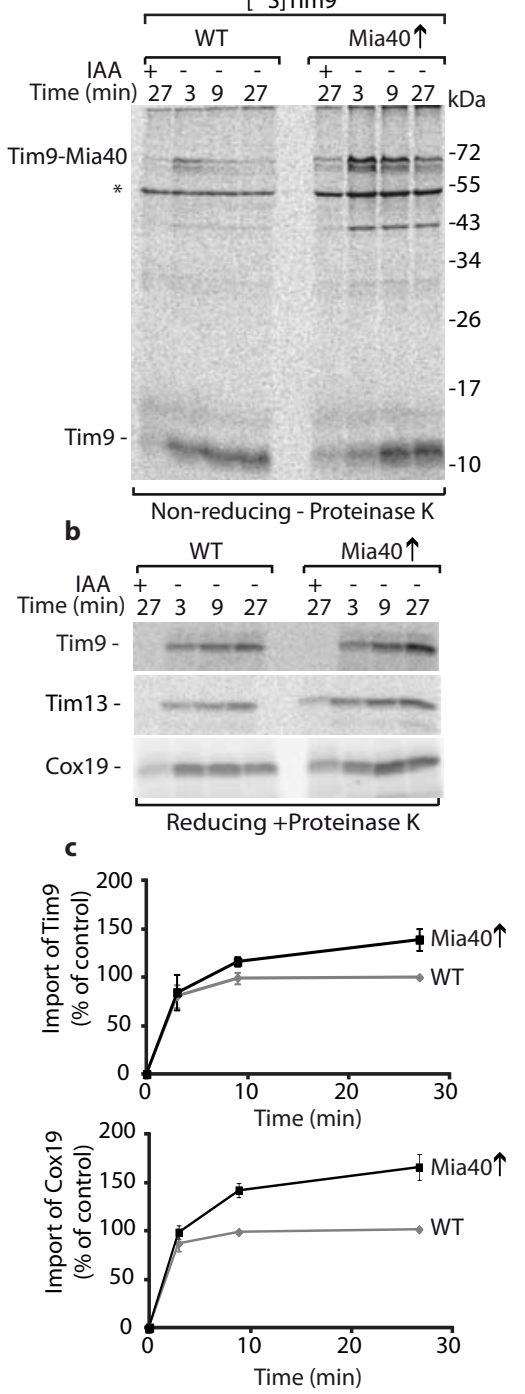

d<smiles>C=CC(=O)OCC(=O)O</smiles>

Mia40 -

Ccs1 -

$-\infty$

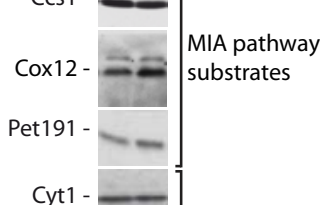

Cyt

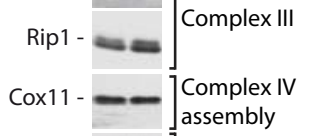

Cср1 - -

Сус3- $-2 \begin{aligned} & \text { Other } \\ & \text { mitochondrial }\end{aligned}$

Sco1- - proteins

Sod 1

Pgk1 -

Rpt5 -

Ssa1

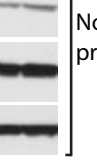

Non-mitochondrial

proteins

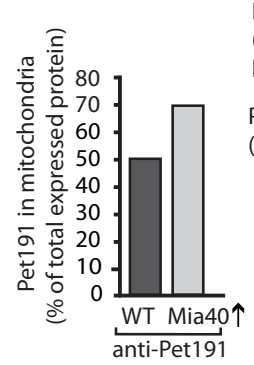

f

Pet191FLAG (anti-Pet191)

Pet191 FLAG (anti-Pet191) higher expo

Pet191FLAG

(anti-FLAG)
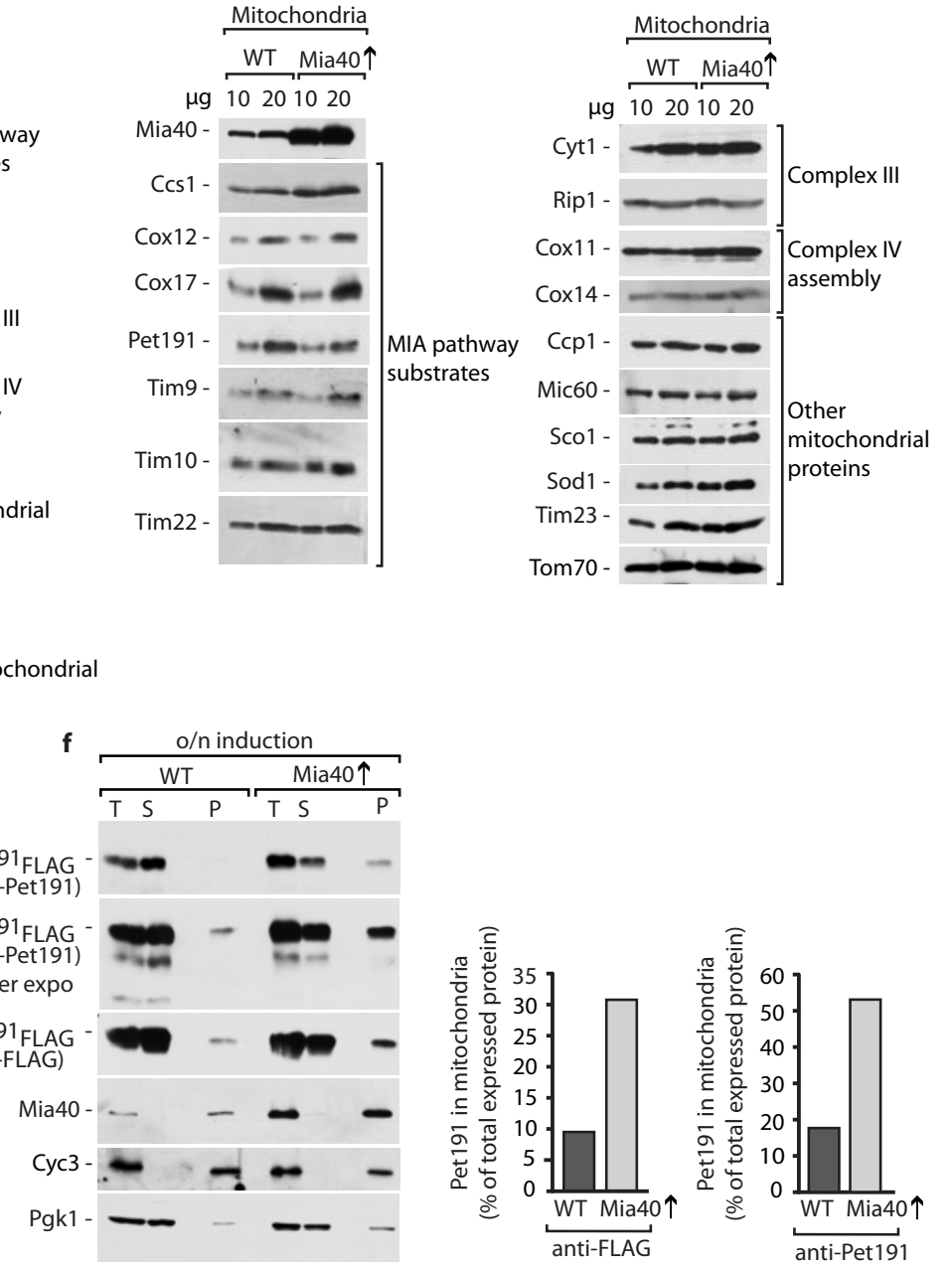

Extended Data Figure 5 Wrobel, Topf et al - revised 3 
a

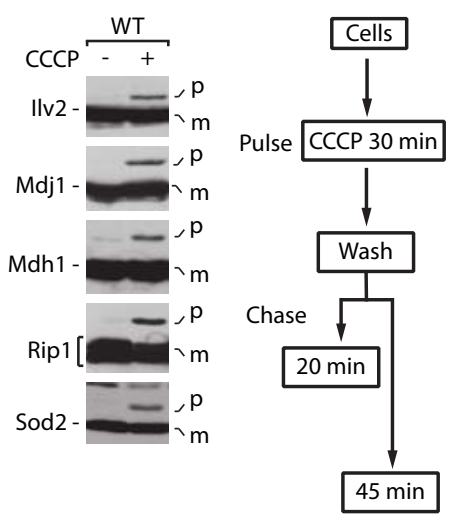

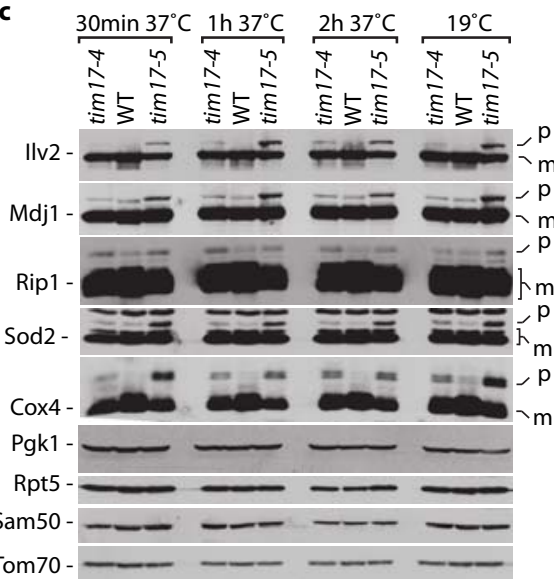

g
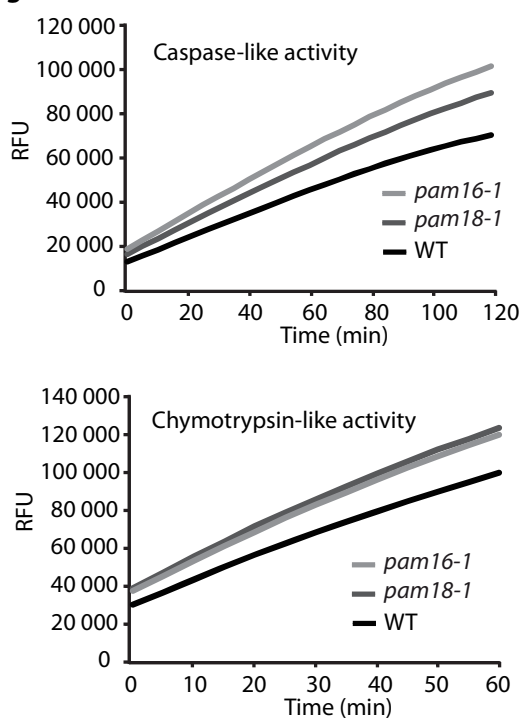

d

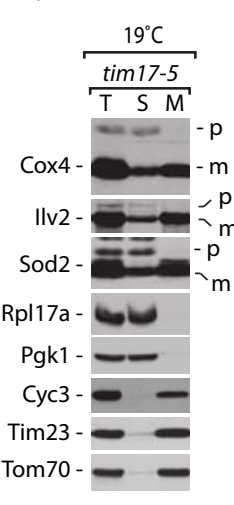

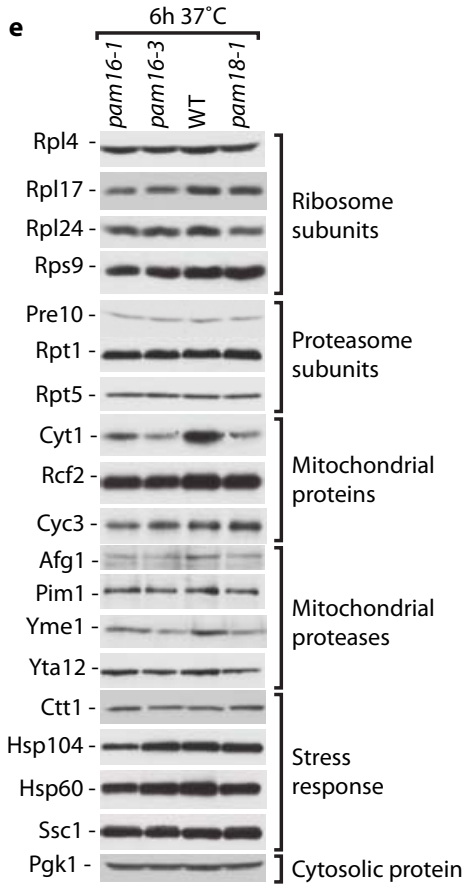

h
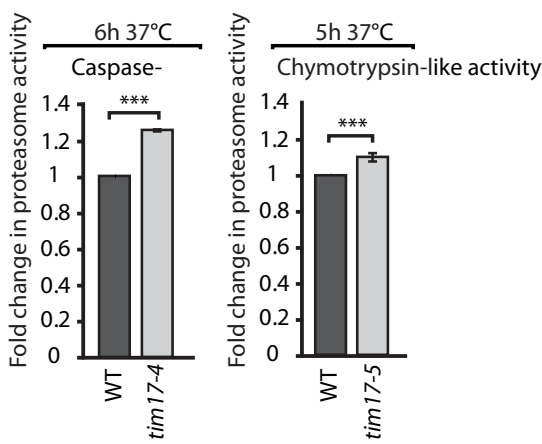
Chymotrypsin-like activity

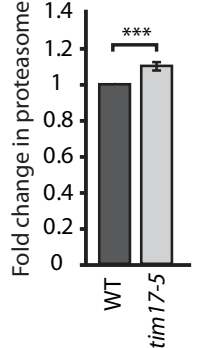

i

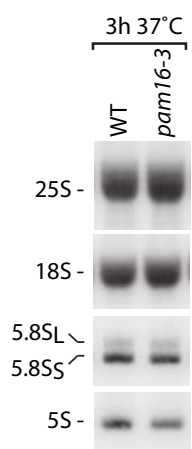

j $1 \mathrm{~h}\left[{ }^{35} \mathrm{~S}\right]$ Pulse $2 \mathrm{~h}\left[{ }^{35} \mathrm{~S}\right]$ Pulse
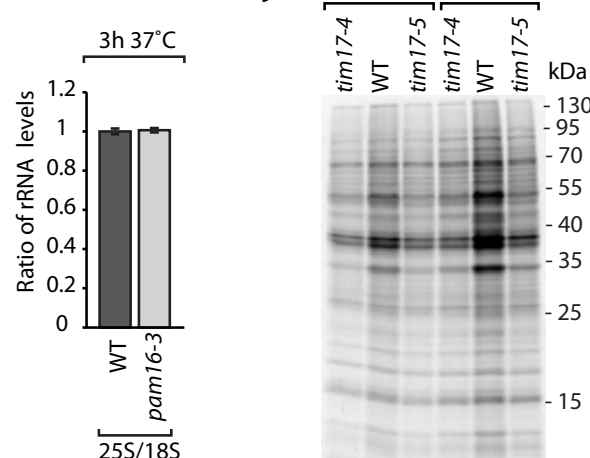

$25 \mathrm{~S} / 18 \mathrm{~S}$

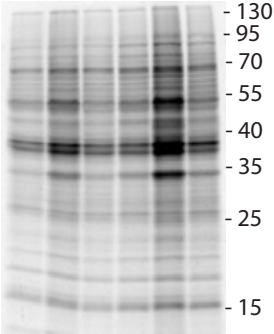

k

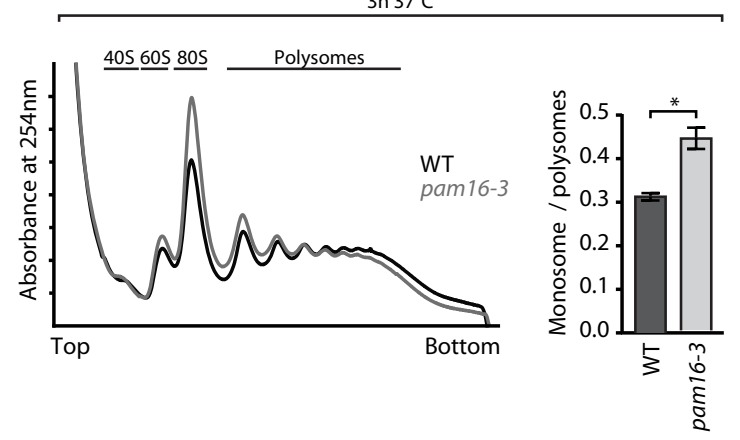

Pgk1 - $\frac{---1}{2 \mathrm{~h} 37^{\circ} \mathrm{C}} \frac{-}{3 \mathrm{~h} 37^{\circ} \mathrm{C}}$

Extended Data Figure 6 Wrobel, Topf et al - revised 3 

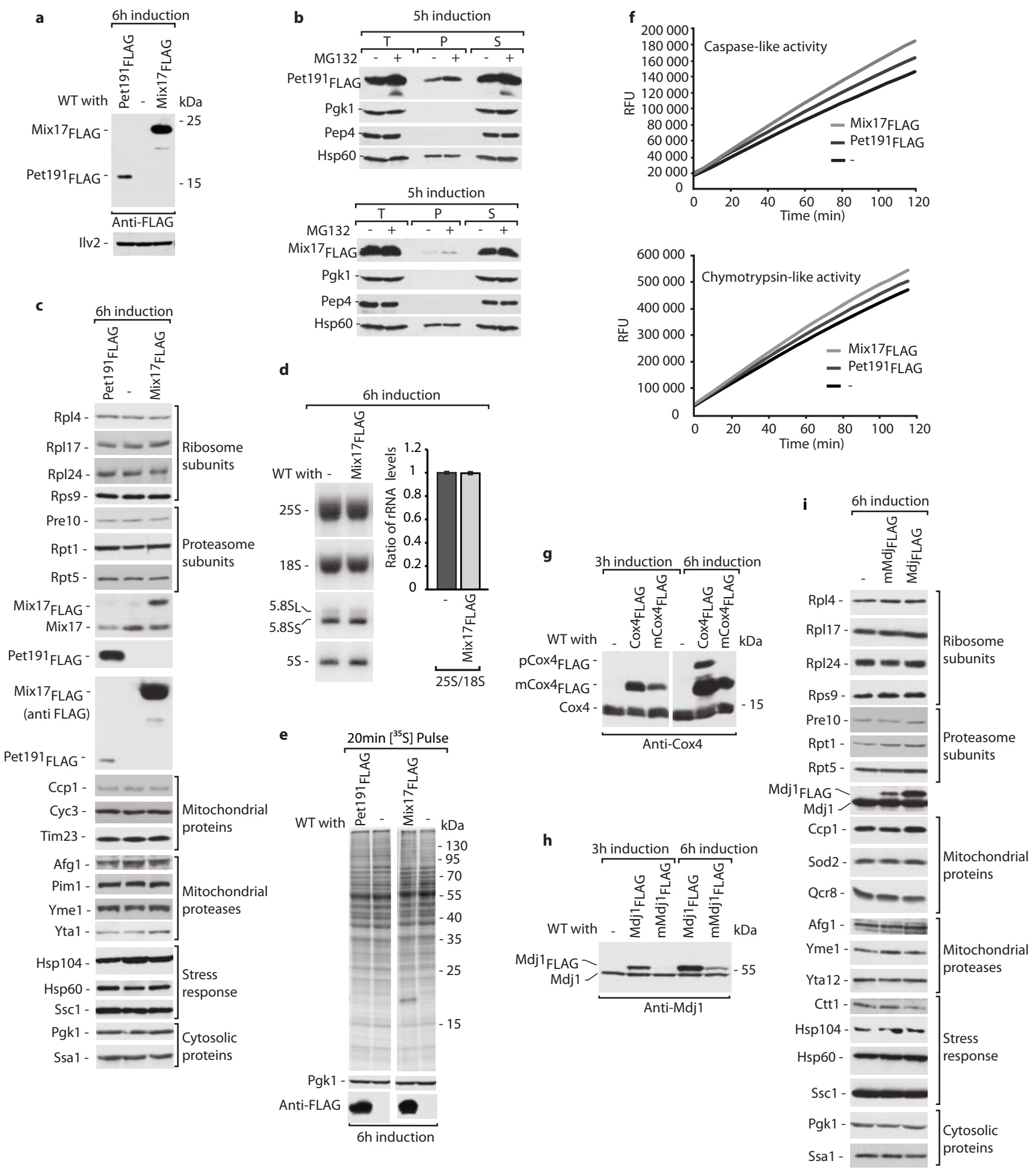

Extended Data Figure 7 Wrobel, Topf et al -revised 3 
a

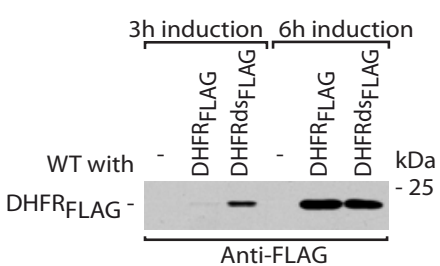

c
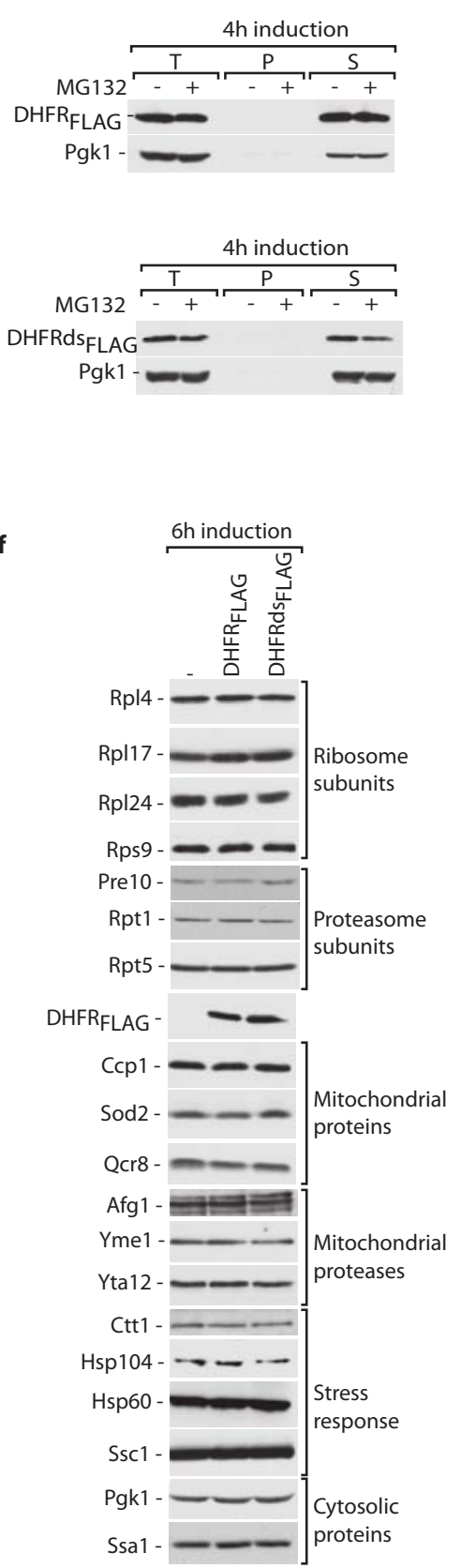

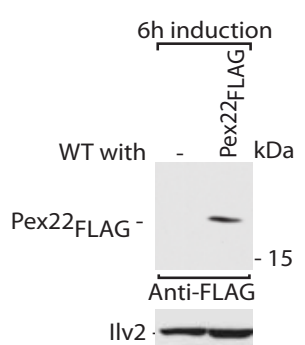

d
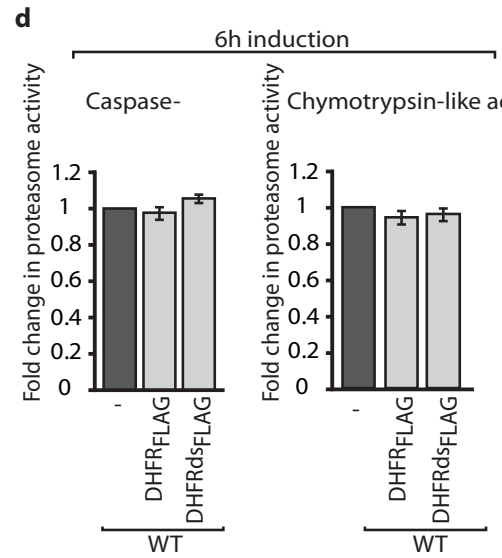

g

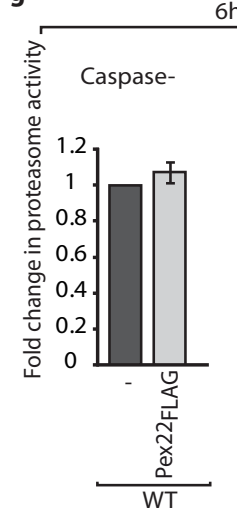

$6 \mathrm{~h}$ induction

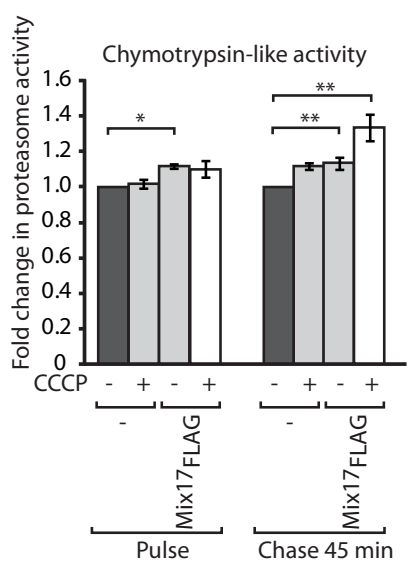

b

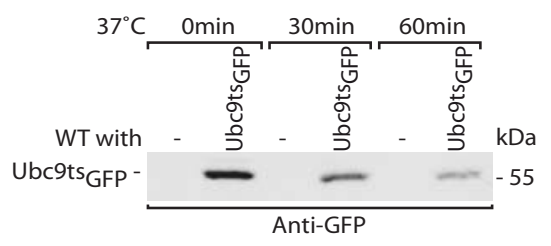

e 50000
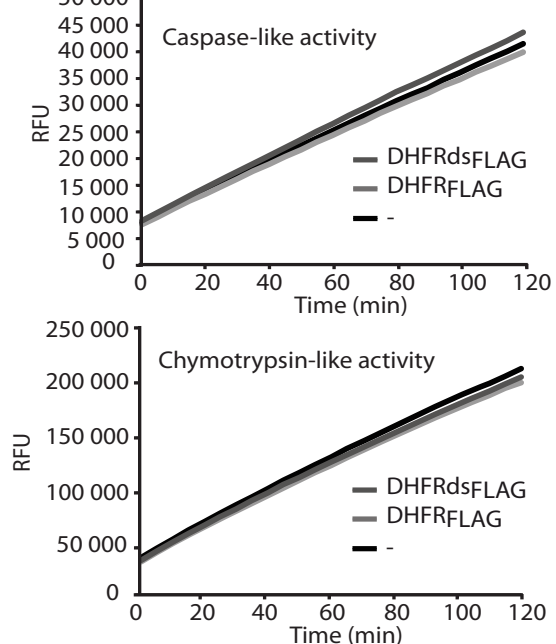

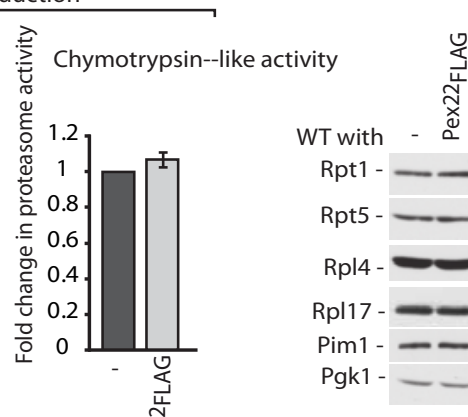
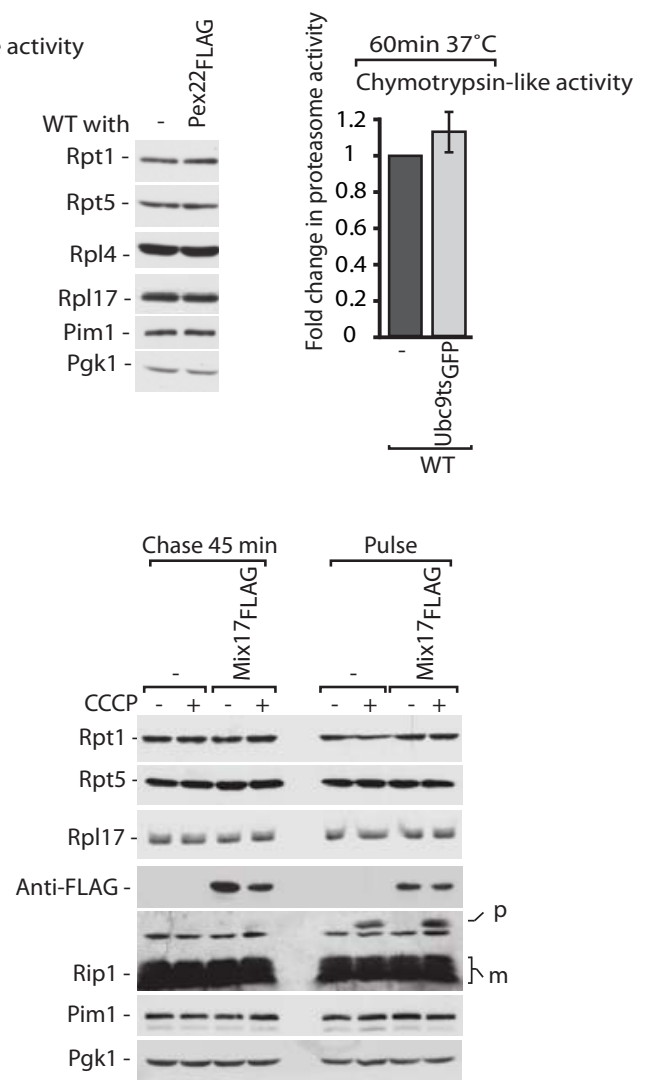

Extended Data Figure 8 Wrobel, Topf et al - revised 3 
a
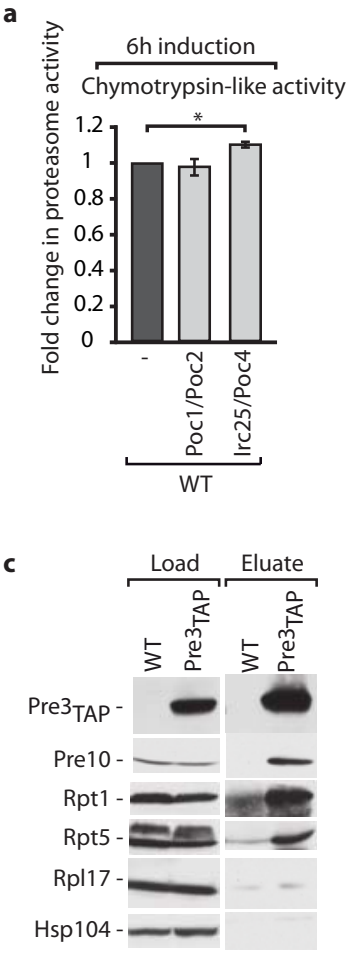

b
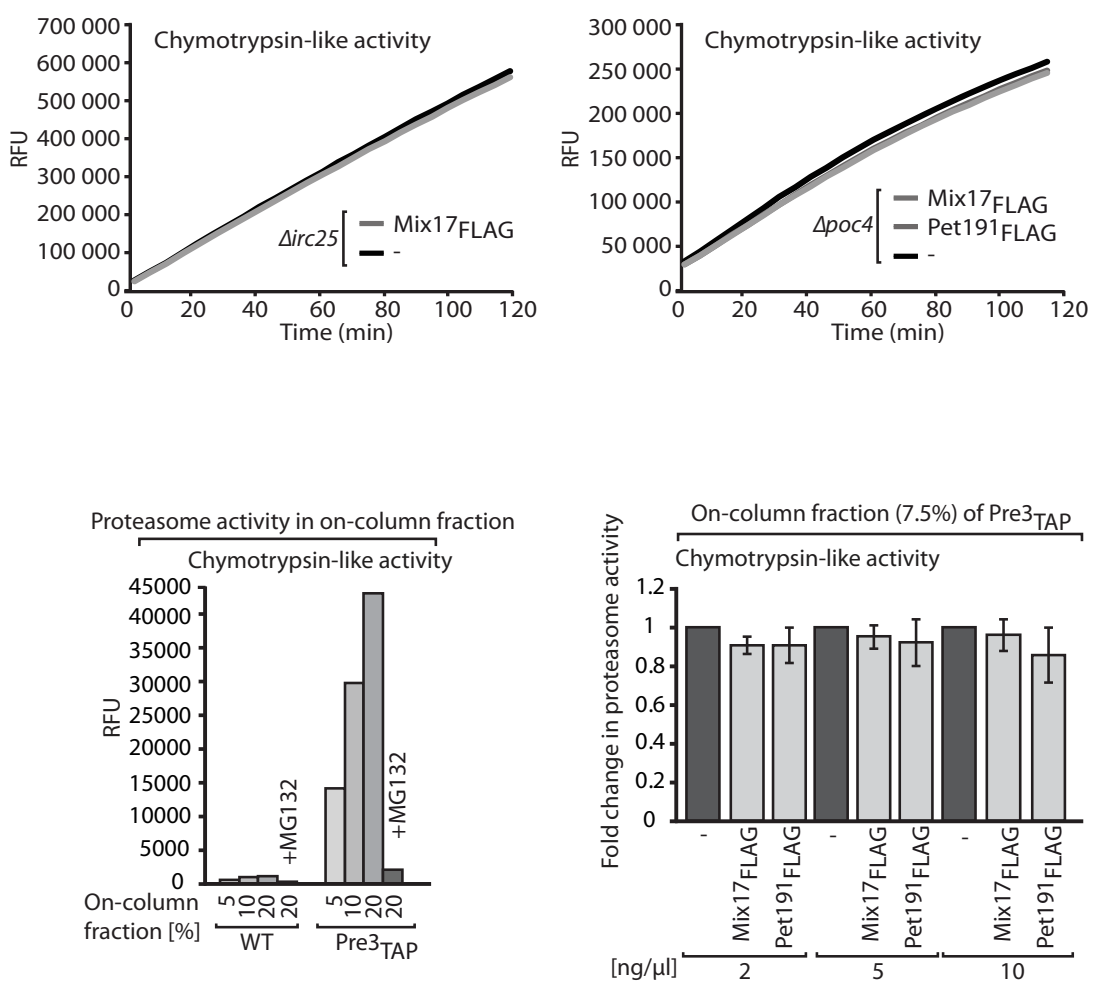

d

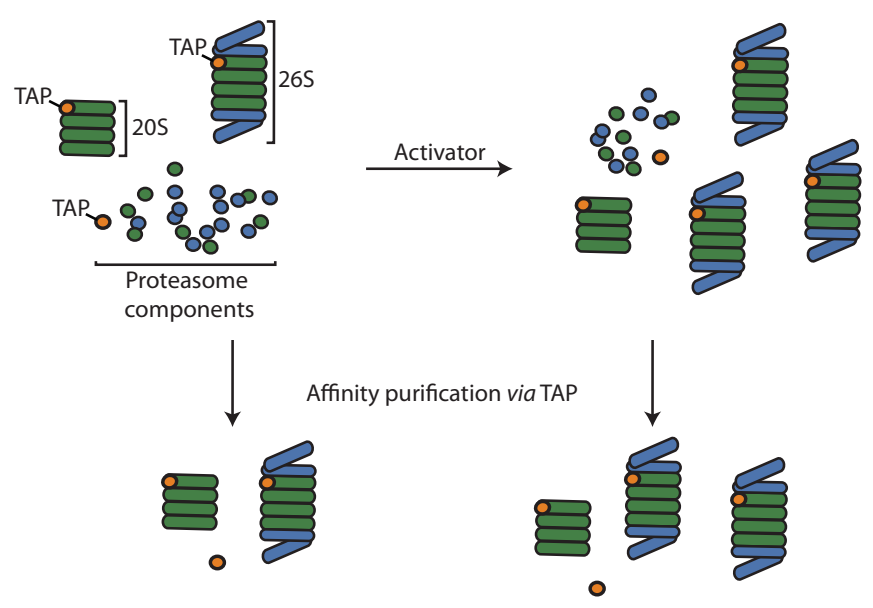

Extended Data Figure 9 Wrobel, Topf et al - revised 3 

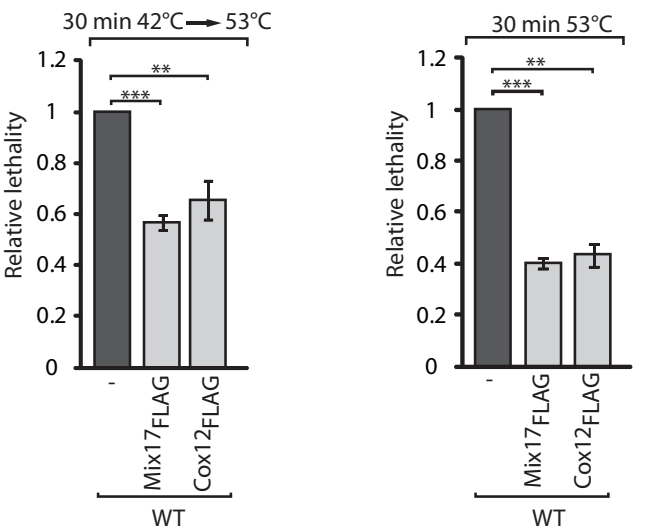

b
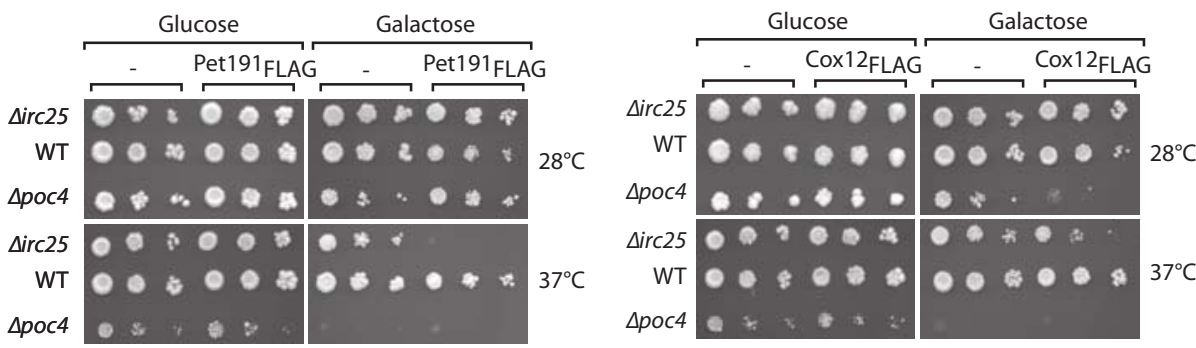

c

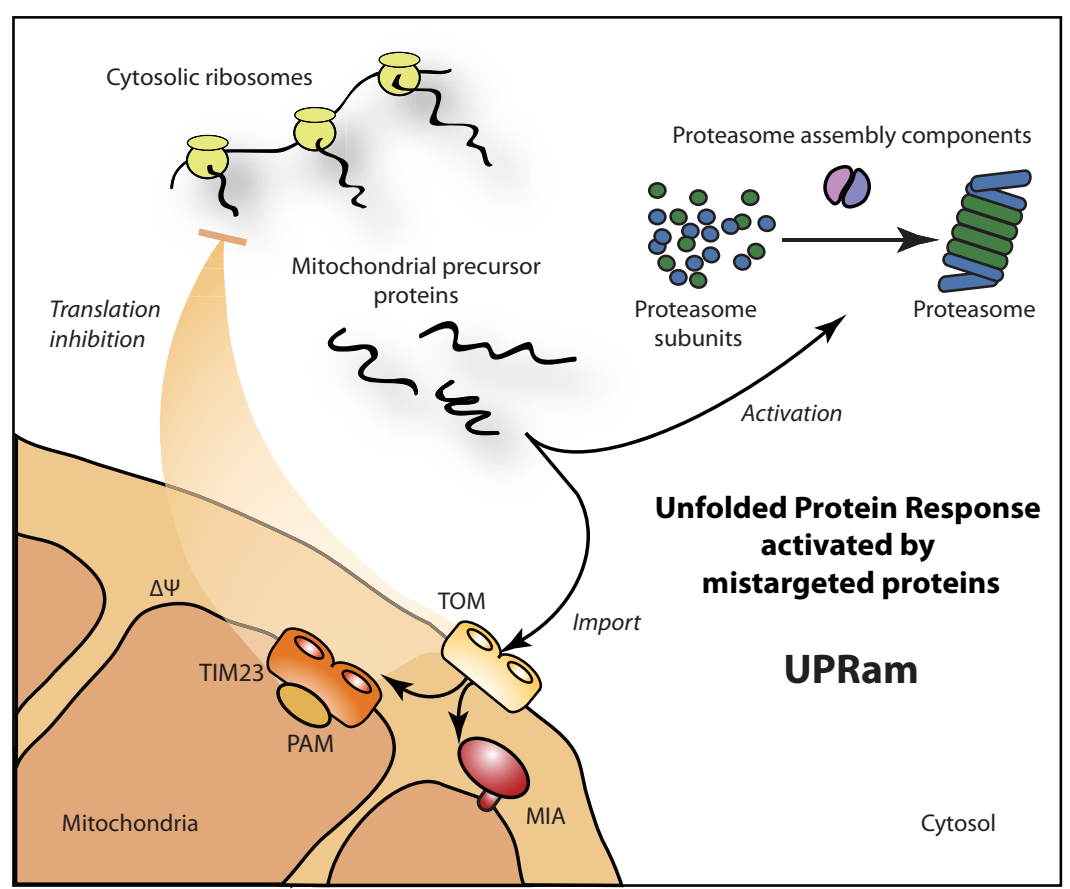

Extended Data Figure 10 Wrobel, Topf et al - revised 3 